


\section{MATERIALS FOR FUEL CELLS}

C. K. Chiang, M. I. Cohen, A. L. Dragoo, and A. D. Franklin

\section{U.S. DEPARTMENT OF COMMERCE}

National Bureau of Standards

National Measurement Laboratory

Washington, DC 20234

Final Report--January 1979 to December 1979

Issued January 1984

Prepared for

Division of Fossil Fuel Utilization

Department of Energy

Washington, DC 20545

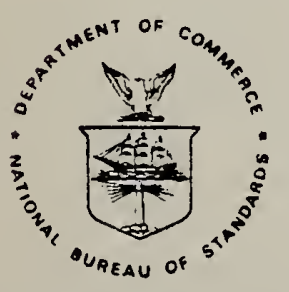

U.S. DEPARTMENT OF COMIMERCE, Maicolm Baldrige, Secretary NATIONAL BUREAU OF STANDARDS, Ernest Ambler, Director 

Table of Contents

Abstract . . . . . . . . . . . . . . . . . . 7

1. Introduction. . . . . . . . . . . . . . . . . 9

2. Subtask Reports ................... . . 10

2.1 High Temperature Solid Electrolytes........... 10 Introduction .................. 10

2.1.1 Preparation and Characterization of High-Density Ceria-Yttria Ceramics. . . . . . . . . . 13 Introduction .............. 13 Coprecipitation. . . . . . . . . . 14 Experimental Details........... 17 Results and Discussion.......... 22 Summary. . . . . . . . . . . . . 32 Acknowledgments. . . . . . . . . . . 33

2.1.2 Electrical Proprties of $\mathrm{Y}$-doped $\mathrm{CeC}_{2}$ Ceramics Comparison of ac and dc Measurements . . . . . 34 Introduction ............... 34

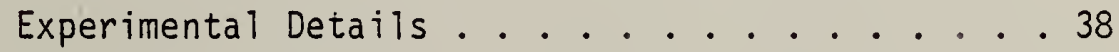
Results................. 40 Discussion ..................... 47 Summary. . . . . . . . . . . . . . 50

2.1.3 Slow Transients in $\mathrm{Y}$-doped $\mathrm{CeO}_{2}$. . . . . . 51 2.1.4 Precipitation Phenomena in $\mathrm{Mg}$-doped $\mathrm{ZrO}_{2}$. . . . 53 
2.2 Interconnector Materials . . . . . . . . . 54

2.2.1 Oxygen Sensitive Electrode Impedance in Sr-doped $\mathrm{LaCrO}_{3}$.............. . . 54 Introduction . . . . . . . . . . 54 Results.............. . . 55

Summary. . . . . . . . . . . . 58

2.3 Development of Instruments . . . . . . . . . . 59

2.3.1 Low Frequency and Pulse Operation of MicroprocessorControlled Potentiostat. . . . . . . . 59 Introduction . . . . . . . . . . 59 Hardware ............. . . 59 Software: Interfacing to a Commercially-Available Operating System ...........63 References .................. . . . . . . . . . 66 
Tables

1. Flame emission/atomic absorption analyses for selected impurities, ppm.

2. X-ray diffraction results (CuK $\alpha, \lambda=1.54178 \AA$ )

3. Effective crystallite dimensions, $L_{h k}$

4. Determinations of the lattice constant of $\mathrm{CeO}_{2}: \mathrm{YO}_{1.5}$

5. Equivalent circuit parameters for $\mathrm{Y}$-doped $\mathrm{CeO}_{2}$ ceramic specimens at $230-250{ }^{\circ} \mathrm{C}$.

6. Comparison of total ac with 4-probe de conductivities at $500{ }^{\circ} \mathrm{C}$ for "chemically-prepared" 8.5 cation per cent $Y$-doped $\mathrm{CeO}_{2}$ ceramics.

7. Activation energies for ac and dc conductivities in "chemicallyprepared" 8.5 cation percent $\mathrm{Y}$-doped $\mathrm{CeO}_{2}$ ceramic.

8. Addressing requirements, disk driver-converter section. 
Figures

1a: Agglomerated particle from a precipitation of $\mathrm{Ce}-\mathrm{Y}$ hydroxide by the addition of ammonium hydroxide to a nitrate solution.

1b: Fracture surface of a sintered specimen which was fabricated from a powder containing particles such as the one shown in Figure la.

2: Schematic of the precipitation procedure.

3: SEM Micrographs of the precipitate and oxide powder: (a) the initial precipitate; (b) the aged precipitate; (c) the oxide powder obtained by calcining the precipitate at $620^{\circ} \mathrm{C}$.

4: Micrographs of HP YDC: (a) fracture surface formed during hotpressing, chemically etched to reveal grain boundaries; (b) mechanically fractured surface, chemically etched; (c) bright field STEM image of ion-beam thinned specimen [28].

5: Equivalent circuit used to represent the impedance data for $Y$-doped $\mathrm{CeO}_{2}$ ceramics. The circuit elements and parameters are explained in the text.

6: Impedance data in the complex plane for "mixed oxide" specimen 83 at $241{ }^{\circ} \mathrm{C}(\mathrm{a})$, and "chemically-prepared" specimen $\mathrm{B} 7$ at $251{ }^{\circ} \mathrm{C}(\mathrm{b})$. The observed data are indicated by squares, and the values calculated for the same frequencies from the equivalent circuit, as described in the text, are reprasented by pluses. The drawn arcs represent the behavior of $R_{L}$ in parallel with $C_{g}$ (left-hand arc) and $z_{j}$ in series with $R_{L}$ (right-hand arc).

7: Temperature dependence of the conductivity of "chemically-prepared" $Y$-doped $\mathrm{CeO}_{2}$ ( 8.5 cation percent) ceramic, measured by the 4-probe dc method. 
8: Impedance data in the complex plane for a "chemically-prepared" ceramic specimen of 8.5 cation percent $Y$-doped $\mathrm{CeO}_{2}$ at $713^{\circ} \mathrm{C}$. The electrodes are sputtered Au/Pd a1loy. The observed data are indicated by squares and the calculated by pluses. See text for details.

9: Comparison of temperature dependence of 4-probe and ac conductivities of "chemically-prepared" $Y$-doped $\mathrm{CeO}_{2}$ ( 8.5 cation percent) ceramic. The symbols,,$+ \Delta$, and 0 refer to different ac specimens; $x$ indicates the 4-probe dc data on a fourth specimen.

10: Dependence of $R_{j} / R_{L}$ at $\sim 240{ }^{\circ} \mathrm{C}$ upon porosity for "mixed oxide" specimens of 10-20 cation percent $Y$-doped $\mathrm{CeO}_{2}$ ceramics. The dotted line is the least-squares line through the origin. The solid lines are solutions to Eqn. [3] for $\varepsilon=30, x=0$ and the values of $a / b$ shown.

11: Effect on complex impedance of $2 r_{0.919} \mathrm{Ma} 0.081^{\circ} 1.979$ at $446{ }^{\circ} \mathrm{C}$ in air of precipitation of tetragonal phase. The solution-annealed specimen is indicated by $x$, the precipitation-annealed by 0 . The insert shows the vector difference.

12: Phase diagram of $\mathrm{MgO}$-rich portion of the $\mathrm{MgO}_{-}-\mathrm{ZrO}_{2}$ binary, after Grain, ref. (76).

13: Typical impedance spectrum ( $5 \mathrm{~Hz}$ to $13 \mathrm{MHz}$ ) of $\mathrm{La}_{0.992} \mathrm{Sr}_{0.008} \mathrm{CrO}_{3}$ at room temperature, equilibrated with tank $\mathrm{N}_{2}$ at $52{ }^{\circ} \mathrm{C}$. The high frequency region contains a temperature-dependent fine structure. Inset shows this fine structure revealed by making measurements at $-130^{\circ} \mathrm{C}$. 
14: Time dependence of the electrode resistance of Au electrodes on $\mathrm{La}_{0.992} \mathrm{Sr}_{0.008} \mathrm{CrO}_{3}$ at $52{ }^{\circ} \mathrm{C}$. Open circles represent data taken when the atmosphere was switched from tank $\mathrm{N}_{2}$ to tank $\mathrm{O}_{2}$. Filled circles are for the reverse. 


\section{Abstract}

The preparation of very dense $\mathrm{Y}$-doped $\mathrm{CeO}_{2}$ ceramic is described, by hot-pressing powders obtained by the homogeneous precipitation of mixed cerium and yttrium carbonates from trichloracetate solutions. The resulting ceramic was very homogeneous, judging by the sharpness of the $x$-ray diffraction peaks, had a density of $99.4 \pm 0.06$ percent of the theoretical fully-dense value for the composition, and exhibits equiaxed grains with diameters in the range from one to four $\mu \mathrm{m}$.

Diffusion equations have been written in finite-difference form for the flow of neutral atomic oxygen into or out of an oxygen-ion-conducting solid electrolyte specimen through which a constant oxygen-ion flux is maintained. The neutral oxygen diffuses to or from the electrode/ electrolyte interface simultaneously through the electrode and the electrolyte. The slow establishment of a steady-state gradient in oxygen activity produces a slowly-changing voltage difference between two potential probes placed along the specimen axis. This potential difference exhibits a number of the features we have seen in the slow transients observed when measuring the dc resistance of $Y$-doped $\mathrm{CeO}_{2}$ ceramics by the 4-probe method.

Measurements of the impedance of $\mathrm{Y}$-doped $\mathrm{CeO}_{2}$ ceramics containing about ten or 20 cation percent $Y$ indicate that there is a sizable contribution from inhomogeneities, perhaps grain boundaries, to the total impedance. Separating the intrinsic or lattice impedance from the inhomogeneity contribution appears to be possible using the frequency response of the impedance. The intrinsic conductivity is somewhat, but not heavily, dependent upon the specimen preparation. Values obtained here for the activation energy and pre-exponential factor for this 
intrinsic conductivity (oT plot) are in reasonable agreement with values from the recent literature.

The inhomogeneity contribution to the impedance, and particularly the equivalent parallel capacitance, appears to be strongly dependent on the specimen preparation. For "mixed oxide" materials, the ratio of the inhomogeneity resistance to the intrinsic resistance scales approximately linearly with porosity, but the connection appears to be indirect. The existence of regions, perhaps at the grain boundaries, of variable dopant concentration is a possible explanation, with the incidence of such regions correlating with porosity. For the "chemically-prepared" materials, a much larger equivalent inhomogeneity capacitance is observed than with "mixed oxide" materials. The differences cannot be accounted for on the basis of grain boundary geometry, but may reflect again a chemical effect at grain boundaries, such as an increase in the concentration of electronic charge carriers.

With polycrystalline specimens of materials of this kind, the use of impedance spectroscopy, the analysis of the frequency dependence of the impedance over a wide frequency range, appears to be essential to a full understanding of the mass and charge transport processes.

The impedance of partially-stabilized zirconia (Mg-doped $\left.\mathrm{ZrO}_{2}\right)$ annealed at temperatures at which particles of tetragonal $\mathrm{ZrO}_{2}$ solid solution are expected to precipitate out, when compared to material annealed wholly in a single-phase region, exhibits an additional relaxation. We attribute this to the presence of the precipitate particles, with resistivity and/or dielectric constant somewhat different from that of the matrix.

Barrier layers are formed on $\mathrm{Sr}$-doped $\mathrm{LaCrO}_{3}$ that give rise to an appreciable electrode impedance with electrodes of Au or Pt. The 
corresponding electrode resistance is quite sensitive to the oxygen activity in the atmosphere, following atmospheric changes at temperatures near room temperature with time constants of the order of minutes or days. The electrical properties of these barrier layers at room temperature do not conform to the usual models of Schottky layers on semiconductors, but exhibit changes in current and differential capacitance much more symmetrical in the applied bias.

Work is continuing on adapting the microprocessor-controlled potentiostat to $10 w$-frequency and pulse operation, to allow, especially, solid-electrolyte impedance measurements in the low-frequency range. This work has mainly been involved in redesigning a new converter board and in developing software to allow interfacing with a commerciallyavailable Operating System.

\section{Introduction}

The program of research on materials for fuel cells and batteries at the National Bureau. of Standards includes work on both liquidelectrolyte and solid-electrolyte systems. Formerly, progress in both topics was reported in the same report, but starting this Fiscal Year will be covered in separate reports. This report deals with work on solid-electrolyte systems.

The overall objectives of the research are:

1. To provide data allowing selection of optimum materials for critical aspects of fuel cell operations, and

2. To improve the measurement capability and standards for assessment of performance (e.g., efficiency of electrode processes, lifetime of components, etc. L of materials in fuel cells and batteries. The work on materials for solid-electrolyte during this year inyolyed research on materials for several comconents of the overall solid-electrolyte fuel cell. These include: 
1. High Temperature Solid Electrolytes,

2. Interconnector materials, and

3. Development of instruments.

\section{Subtask Reports}

\subsection{High Temperature Solid Electrolytes}

\section{Introduction}

Oxide solid solutions having a defective fluorite structure and based on $\mathrm{ZrO}_{2}, \mathrm{CeO}_{2}$, and $\mathrm{ThO}_{2}$, doped with $\mathrm{CaO}, \mathrm{Y}_{2} \mathrm{O}_{3}$ or the trivalent rare earth oxides, have high oxygen ion mobilities relative to the pure constituent oxides. The high oxygen ion mobilities make these oxide solid solutions potentially useful solid electrolytes for high temperature fuel cells. The high oxygen ion mobility results from the large concentration of oxygen vacancies introduced into the oxygen sublattice of the host oxide. About 5 to 15 mole percent of dopant may be added depending upon the oxide system.

$\mathrm{ZrO}_{2}$-based solid solutions have been used as electrolytes for hightemperature electromotive force measurements since the mid-1930's $[1,2]$, and $\mathrm{ThO}_{2}$-based electrolytes, since 1957 [3]. $\mathrm{ZrO}_{2}$-based electrolytes have been studied for fuel cell applications principally at Westinghouse and G. E. in the United States, and elsewhere in France, Germany and the Soviet Union. Recent results $[4,5]$ on $\mathrm{CeO}_{2}: \mathrm{Ln}_{2} \mathrm{O}_{3}$, where $\mathrm{Ln}$ represents a variety of lanthanide ions or $\mathrm{y}^{3+}$, have revealed oxygen-ion conductivities essentially equivalent to that of $\mathrm{ZrO}_{2}: \mathrm{CaO}$ but at temperatures about $200{ }^{\circ} \mathrm{C}$ lower. Thus, fuel cells using a $\mathrm{CeO}_{2}$-based electrolyte might operate at about $800^{\circ} \mathrm{C}$ as compared to $1000{ }^{\circ} \mathrm{C}$ for $\mathrm{ZrO}_{2}$-based electrolytes. However, Ce-based electrolytes begin to show appreciable electronic conduction at higher oxygen partial pressures than do the $\mathrm{ZrO}_{2}$-electrolytes; for example, one-half of the electrical conductivity 
is electronic in $\left(\mathrm{CeO}_{2}\right)_{0.95}\left(\mathrm{Y}_{2} \mathrm{O}_{3}\right)_{0.05}$ at $\mathrm{P}_{\mathrm{O}_{2}}=10^{-14}$ atm $\left(\sim 10^{-19} \mathrm{~Pa}\right)$ for $T=800{ }^{\circ} \mathrm{C}$, whereas for $\mathrm{ZrO}_{2}: \mathrm{CaO}, \mathrm{P}_{\mathrm{O}_{2}}=2.5 \times 10^{-31} \mathrm{~atm}(2.5 \times$ $\left.10^{-36} \mathrm{~Pa}\right)$ for $\rightarrow 1000{ }^{\circ} \mathrm{C}[6]$.

At the high oxygen vacancy concentrations present in these electrolytes, the oxygen vacancies are probably nearly all associated with the dopant cations [7]. If these electrolytes undergo prolonged anneals at moderate temperatures $\left(<1000^{\circ} \mathrm{C}\right)$, the oxygen vacancies, and perhaps to a lesser extent, the dopant cations, may order into a structure coherent with the fluorite structure of the host oxide. Formally, in terms of a coherent structure, the ionic conductivity of the electrolyte may decrease (resistance may increase) because the vacancies, relative to the fluorite structure, must then move cooperatively.

The existence of coherent structures is well documented for $\mathrm{ZrO}_{2}{ }^{-}$ based solid solutions [8-15]. Coherent structures in $\mathrm{CeO}_{2}$-based solid solutions have not been identified.

Carter and Roth [12] found that the increase in resistance of calcia-stabilized zirconia (CSZ) when annealed at $<1000^{\circ} \mathrm{C}$ was associated with the formation of coherent structures, observed as superstructure in neutron and $x$-ray diffraction. This "aging" of CSZ could be reversed ("deaged") by annealing at $1400{ }^{\circ} \mathrm{C}$. In a high temperature fuel cell aging of the electrolyte would reduce the efficiency of the cell.

A second aging process which may alter the long-term performance of a high temperature fuel cell electrolyte is the redistribution of the dopant cations along the grain boundaries. Relative to the lattice, the dopant cations appear as negative charges. Thus, they can be expected to migrate under the influence of an applied field. Although the mobility of these cations within the interior of the grain is negligibly 
small for practical purposes, their mobility in the grain boundaries can be significant. For example, from the tracer diffusion measurements for $\mathrm{Ca}^{2+}$ ions in CSZ [16], the time required for $\mathrm{Ca}^{2+}$ ions to cross a $20 \mu \mathrm{m}$ thick electrolyte film with a potential difference of $0.8 \mathrm{~V}$ is on the order of hundreds of years. On the other hand, the same tracer diffusion study showed that migration of $\mathrm{Ca}^{2+}$ ions in the grain boundaries is perhaps 1000 times larger at $1800{ }^{\circ} \mathrm{C}$ than the bulk diffusion rate, a ratio that would be expected to be even larger at lower temperatures. Hence, migration of the dopant ions along grain boundary paths over significant distances during times of the order of a year or less can be expected in all of the fluorite-structure oxides of current interest as solid electrolytes.

The migration of dopant ions along grain boundaries can be expected to result in at least three deleterious effects: (1) a build-up of a resistive layer at either electrolyte boundary, (2) a build-up of a space charge at the electrodes resulting effectively in an overvol tage, and (3) a possible interference with the electrode reaction due to a change in electrolyte composition at the electrolyte-electrode boundaries.

The NBS program of studies on high-temperature electrolytes currently contains two elements: a study of degradation mechanisms in $\mathrm{CeO}_{2}$-based oxygen-ion electrolytes and other materials, and the development of the impedance measurement as a method of analyzing fuel cell performance with the particular aim of deveioping a lifetime-prediction test. 


\subsubsection{Preparation and Characterization of High-Density Ceria-Yttria Ceramics}

\section{Introduction}

Yttrium-doped cerium dioxide (YDC), like the perhaps better known calcia- and yttria-stabilized zirconia, is a fluorite-structure oxide into which a great many oxygen vacancies are introduced by substituting trivalent yttrium for quadrivalent cerium. When about 9.5 atom percent $Y$ is substituted for $\mathrm{Ce}$, the ionic conductivity of $\mathrm{YDC}$ at $1000{ }^{\circ} \mathrm{C}$ is about $0.15(\mathrm{ohm} \cdot \mathrm{cm})^{-1}[4]$. At these high concentrations of yttrium--for example, 2.4 percent of the oxygen sites are vacant in 9.5 percent YDC-oxygen vacancies most probably interact and may form ordered structures, given sufficient time to do so.

To obtain research quality specimens for a study of 1ong-term ac impedance behavior of YDC, we investigated means for preparing ceramic specimens which had nearly full density, uniform microstructure, homogeneous composition and high purity. Nearly complete densification was required in order to avoid changes in the electrical properties arising from rearrangement or elimination of pores during the long-term anneals. Uniform microstructure and homogeneous composition were needed so that the material would have a simple and interpretable ac response both for the intrinsic impedance of the grains and for the grain-boundary impedance.

Our early attempts to prepare specimens by calcining, grinding, compacting and thermally sintering (TS) or not-pressing (HP) the mixed oxides resulted in specimens of low density. Bulk densities ranged from 70 to 90 percent of theoretical density (TD) in the case of the TS specimens and from 93 to 94 percent in the case of specimens cut from a hot-pressed billet. The highest densities were obtained if the mixed 
oxides were not calcined prior to sintering. However, the HP ceramic in which an uncalcined oxide blend was used showed the presence of $\mathrm{CeO}_{2}$ related fluorite-structure phase and a $\mathrm{Y}_{2} \mathrm{O}_{3}$-related c-structure phase. The c-structure phase disappeared when the material was annealed at $1550{ }^{\circ} \mathrm{C}$ for 40 hours. Since extensive comminution of calcined oxides was precluded because it was potential source of impurities, a chemical procedure for preparing we11-mixed and reactive ceria-yttria powders was sought.

We have examined several chemical procedures employing coprecipitation from homogeneous solution to prepare Ce-Y compositions. Of these procedures, we have used the coprecipitation of carbonates through the hydrolysis of trichloroacetic acid to prepare a large batch of oxide powder. This powder was used to prepare specimens by hot-pressing and by thermal sintering.

\section{Coprecipitation}

Coprecipitation of components can yield a thoroughly blended powder; however, the precipitation must be designed to avoid the entrapment of large numbers of pores in hard, agglomerated precipitate particles. Such particles result if $C e$ and $Y$ are precipitated inhomogeneously--for example, by neutralizing a Ce-Y nitrate solution with ammonium hydroxide. Figure la is a SEM picture of an agglomerated Ce- $Y$ hydroxide particle obtained by precipitating the hydroxide inhomogeneously from a nitrate solution. Grinding the calcined precipitate with an alumina mortar and pestle did not destroy the pores so that the sintered specimens contained large pores which were reminiscent of the precipitate particles. An example of the pores in one of these specimens is shown in Fig. 16. 


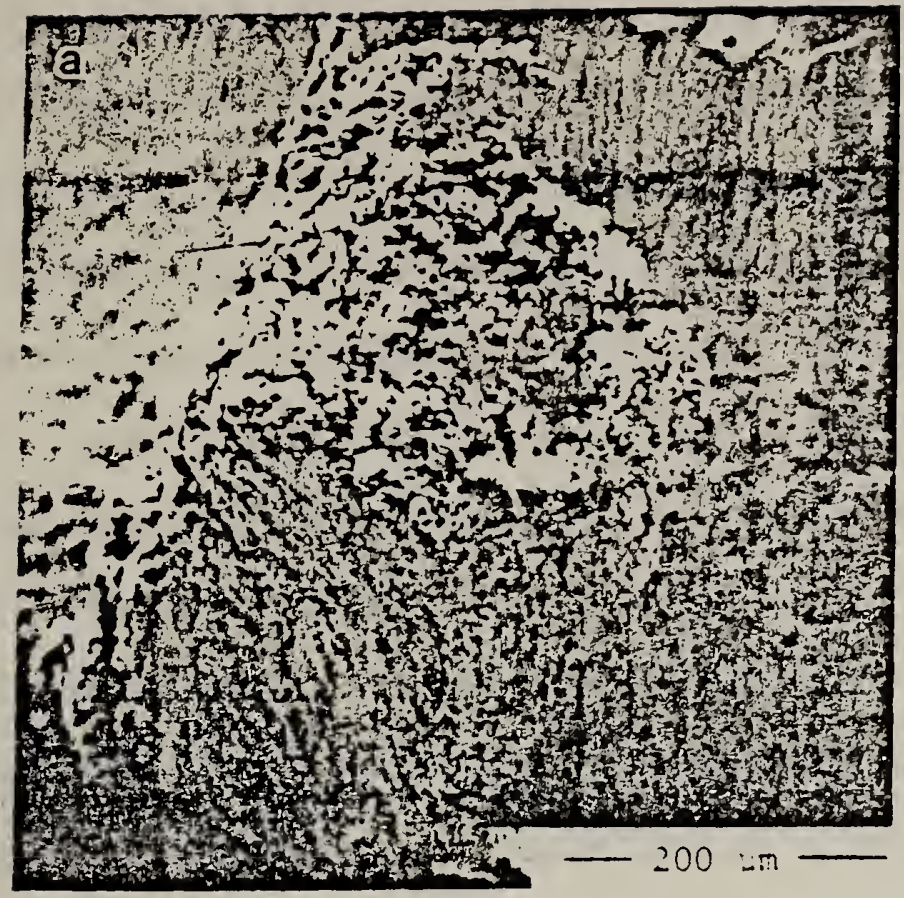

1a: Agglomerated particle from a precipitation of $\mathrm{Ce}-\mathrm{Y}$ hydroxide by the addition of ammonium hydroxide to a nitrate solution.

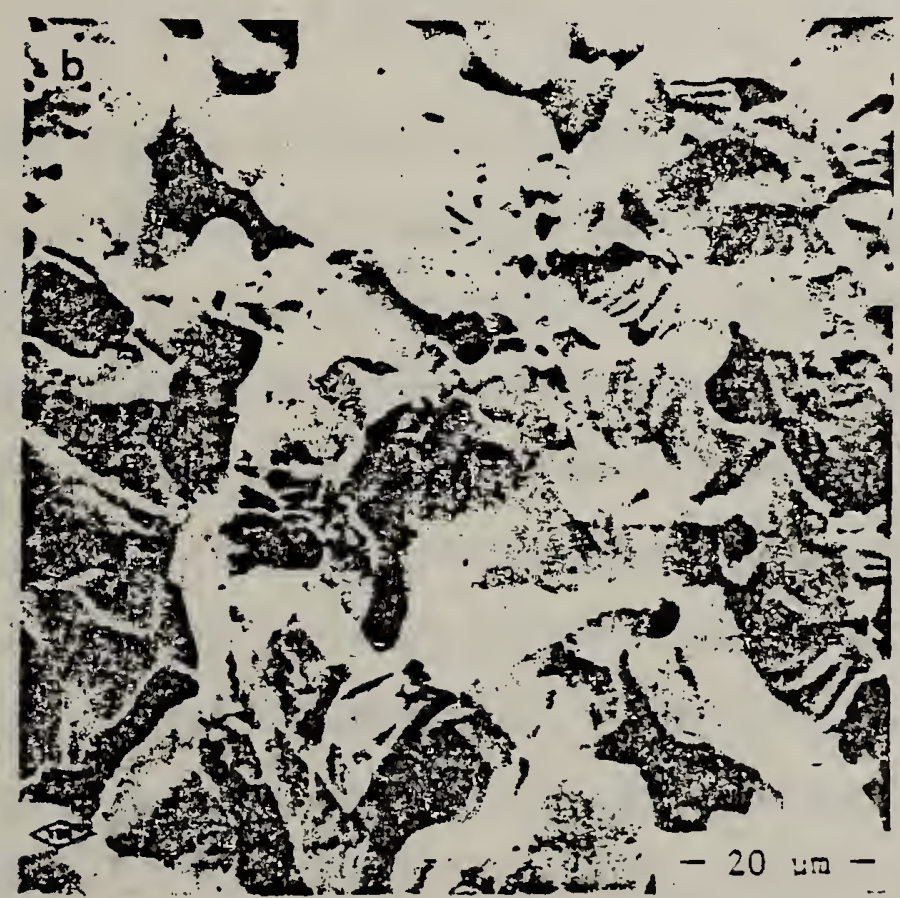

16: Fracture surface of a sintered specimen which was fabricated from a powder containing particles such as the one shown in figure la. 

Willard and Tang [17] were the first to demonstrate the usefulness of precipitation from a homogeneous solution for rapid preparation of a dense precipitate. Subsequent investigators developed a variety of methods for generating the precipitating agent--oxalate, sulfate, iodate, carbonate, etc.--homogeneously throughout the solution and for precipitating a variety of metallic ions. The science and techniques of precipitation from homogeneous solutions have been reviewed by Gordon [18, 19] and by Gordon, et a1. [20].

The precipitation of rare-earth carbonates from homogeneous solution was described first by Salutsky and Quil1 [21], who precipitated the carbonates of La, Nd and Sm by hydrolysis of strong trichloroacetic acid solutions of these rare earths. The reaction proceeds by the decomposition of the trichloroacetate ion [22], and the overall reaction can be written as,

$$
2 \mathrm{Ln}\left(\mathrm{Cl}_{3} \mathrm{CCOO}\right)_{3}+3 \mathrm{HOH}=3 \mathrm{CO}_{2}+6 \mathrm{CHCl}_{3}+\mathrm{Ln}_{2}\left(\mathrm{CO}_{3}\right)_{3},
$$

where Ln designates a trivalent lanthanide ion.

Quill and Salutsky [23] observed that a yellow, gelatinous Ce(IV) trichloroacetate complex formed in hot ceric solutions. Head and Holley [24] prepared a cerous trichloroacetate solution by treating a ceric sulfate solution with hydrogen peroxide, precipitating the cerous hydroxide with urea and dissolving the cerous hydroxide in a slight excess of trichloroacetic acid solution. They investigated the preparation of $\mathrm{Ce}$ carbonate at ambient $\mathrm{CO}_{2}$ pressure and at $\mathrm{CO}_{2}$ pressures of 200-300 and 1000 psig. They identified their product as a hydrated normal carbonate. In contrast, Charles [25] found that a hydrated basic carbonate was obtained if a trichloroacetic acid solution of cerium chloride was used for the hydrolysis reaction. The basic carbonate 
precipitate was observed to be nongelatinous and nearly white. Wendlandt and George [26] prepared a hydrated normal yttrium carbonate using the method of Salutsky and Quill.

Salutsky and Qui11 [21] noted that precipitation of the carbonates did not recover all of the La, Nd or Sm, oxalate having to be added to bring down the remainder of the rare earths from solution. Charles [25] used trichloroacetic acid slightly in excess of the stoichiometric amount for Ce(III) trichloroacetate and obtained a 42 percent yield.

These yields of the carbonates appear to be surprisingly low in view of the low solubility of $\mathrm{Ce}$ and $\mathrm{Y}$ carbonates. Trofimovich and Sedel'nikov [27] determined the solubility of Ce carbonate in water at $25{ }^{\circ} \mathrm{C}$ to be $1.6-2.4 \mathrm{mg} / \mathrm{L}$. Trombe, et al. [28] found a comparably low value for the solubility of $Y$ carbonate. They also observed that the solubility of Ce carbonate was not significantly influenced by $\mathrm{CO}_{2}$ pressure up to one atm.; whereas, the solubility of $Y$ carbonate increased to nearly $40 \mathrm{mg} / \mathrm{L}$ as the $\mathrm{CO}_{2}$ pressures was increased. Quil1 and Salutsky [23] ascribed the failure to obtain a quantitative yield to the formation of some rare earth chloride as a result of the secondary oxidation of the chloroform in the hot solution. In addition to the interference by $\mathrm{Cl}^{-}$-ions, the solubility of $\mathrm{Ce}$ and $Y$ carbonate may be increased by alkali and ammonium ions [29].

The results of previous work indicated that the hydrolys is of trichloroacetic acid could be used to precipitate $C e$ and $Y$ carbonates but that yield and fractionation would be influenced by temperature and concentration of carbonate as well as $\mathrm{Cl}^{-}, \mathrm{NH}_{4}^{+}$, $\mathrm{Na}^{+}$and $\mathrm{K}^{+}$. In this work we attempted to increase the recovery of $\mathrm{Ce}$ and $Y$ by using excess trichloroacetic acid, by adjusting the $\mathrm{pH}$ at the completion of the hydrolysis reaction to slightly alkaline conditions with ammonium bi- 
carbonate to bring down additional $\mathrm{Ce}$ and $\mathrm{Y}$ either as carbonate or as hydroxide, and by ripening the precipitate to increase the particle size, thereby improving the settling out of the precipitate. We obtained a yield of 68 to 70 percent as determined from the oxide recovered from the process.

\section{Experimental Details}

\section{a. Materials}

Cerium dioxide and yttrium oxide $\left(\mathrm{Y}_{2} \mathrm{O}_{3}\right)$ powders of 99.99 percent purity were used as the starting materials. The manufacturer's spectrographic lot analysis indicated the presence of $\mathrm{Mg}, \mathrm{Si}, \mathrm{Ca}$ and $\mathrm{Fe}$ at less than $50 \mathrm{ppm}$ and of other rare earth at less than several hundred ppm. Alkalis were not reported. The first and second rows of Table 1 present flame emission/atomic absorption (FE/AA) analyses of blended $\mathrm{CeO}_{2}-\mathrm{Y}_{2} \mathrm{O}_{3}$ powder and of a specimen hot-pressed with that powder. The $\mathrm{CeO}_{2}$ had a weight loss on ignition (LOI) of 0.865 percent when heated at $1000{ }^{\circ} \mathrm{C}$ for several hours; the $\mathrm{Y}_{2} \mathrm{O}_{3}$ had a 2.3 percent LOI.

$\mathrm{CeO}_{2}$ was dissolved in concentrated nitric acid containing a small amount of hydrofluoric acid [30]*, and the appropriate amount of $\mathrm{Y}_{2} \mathrm{O}_{3}$, dissolved in nitric acid, was added to give stock solutions with cation concentrations in the range of 0.3 to $0.5 \mathrm{~mol} / 1$, and with an average $\mathrm{Ce}-$ Y composition, corrected for LOI, of 90.35 atom percent Ce to 9.65 atom percent $Y$. Since there was some bottle-to-bottle variation in the compositions, the solutions were blended into one another as the contents of the botties were removed.

* Subsequent work has shown that $\mathrm{CeO}_{2}$ can be dissolved much more effaciously in hot concentrated nitric acid to which 30 percent hydrogen peroxide is slowly added than with the nitric acid-hydrofluoric acid used in this work. 
Table 1. Flame Emission/Atomic Absorption Analyses of Selected Impurities, ppm.

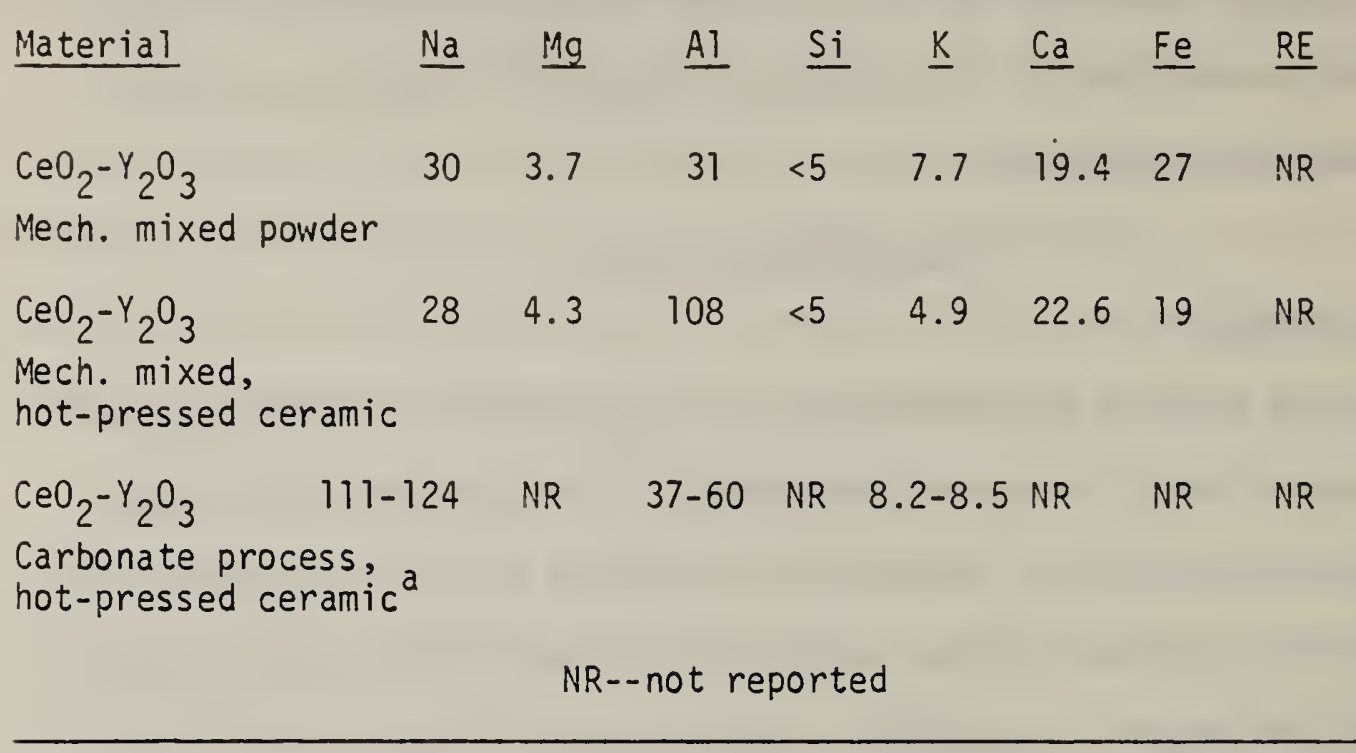

${ }^{\mathrm{a}}$ Two samples 


\section{b. Preparation and Characterization of the Precipitate}

The procedure for preparing the Ce-Y precipitate is diagramed in Fig. 2. About $500 \mathrm{~mL}$ of a stock solution was used for each precipitation. To reduce the nitrate concentration, Ce-Y hydroxides were precipitated by the dropwise addition of an ammonium hydroxide solution (1:2) to the nitrate solution, also diluted 1:2. After the ripened precipitate had settled, the supernatant liquid was siphoned off through a tube closed with a fritted disk to prevent loss of the precipitate. The precipitate was rinsed with distilled water and the supernatant liquid removed as before.

The hydroxide precipitate was dissolved in about three times the stoichiometric amount of a nominally 25 percent trichloroacetic acid solution. To achieve dissolution of the ceric hydroxide, it was necessary to add 30 percent hydrogen peroxide in an amount slightly in excess of a $1: 1$ ratio to the ce content. Upon addition of the hydrogen peroxide, the slurry became brown and a thick layer of foam developed. After about 30 minutes the foaming subsided and a clear solution was obtained.

The solution was diluted to about 31 and was warmed to $80-100{ }^{\circ} \mathrm{C}$ to decompose the trichloroacetic acid. When the reaction was completed, about $20-30 \mathrm{~g}$ of $\mathrm{NH}_{4} \mathrm{HCO}_{3}$ were added to neutralize the solution and to precipitate any $\mathrm{Ce}$ or $\mathrm{Y}$ remaining in the solution. The solution was tested by adding a small amount of $\mathrm{NH}_{4} \mathrm{OH}$. The solution was warmed for about 24 hours to ripen the precipitate and to reduce the volume of the solution. Two or three batches of precipitate were often combined at this point. After the precipitate had settled, the supernatant liquid was pumped off as before, and the precipitate was rinsed three times with water, then with ethanol and finally with acetone. The first 
PREPARATION SCHEME: "CARBONATE PROCESS"

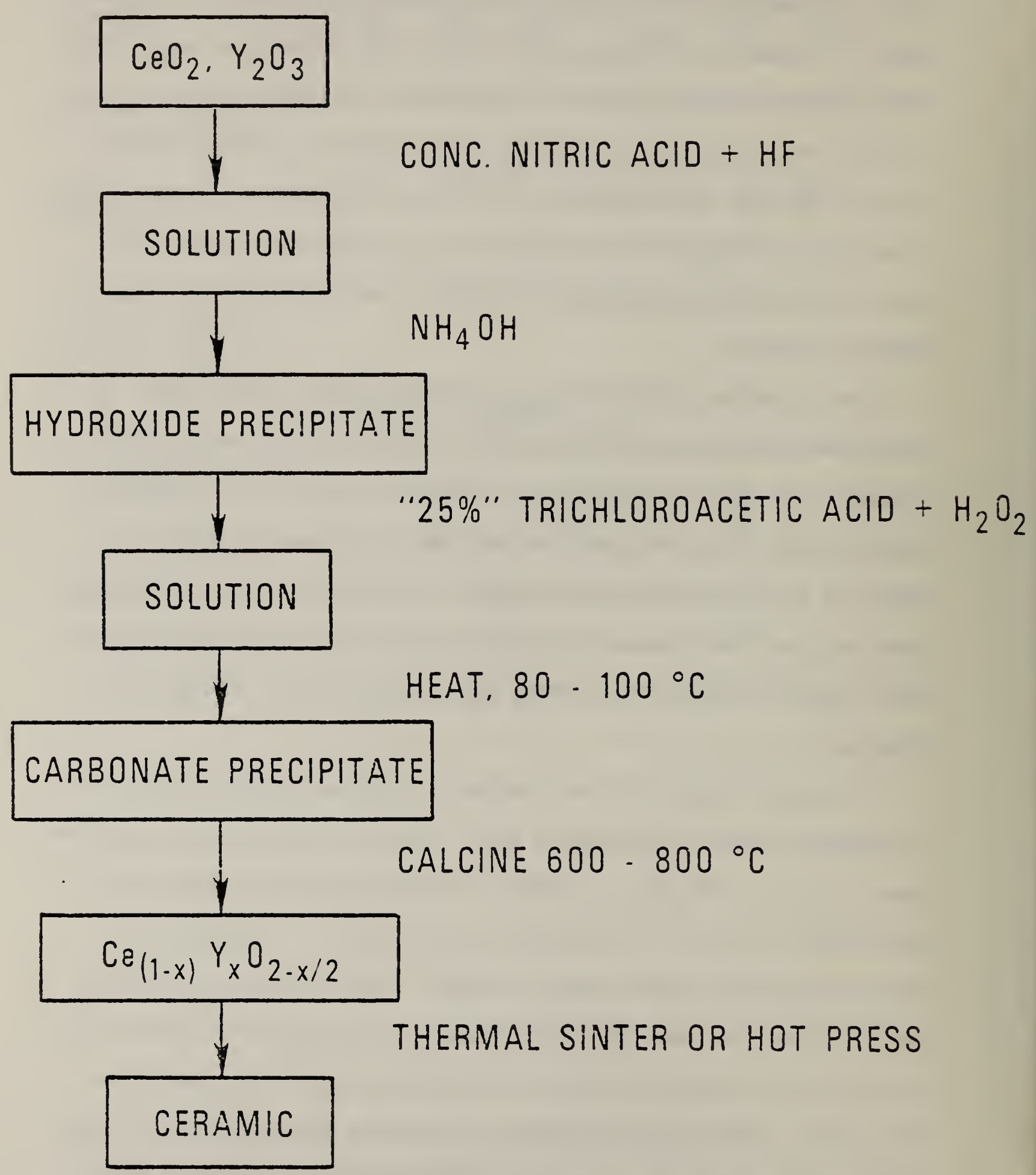

2: Schematic of the precipitation procadure. 
aqueous rinse showed cloudiness when tested with silver nitrate, but the third rinse remained clear. The precipitate was dried first in air and then in a vacuum oven at $60^{\circ} \mathrm{C}$. About $880 \mathrm{~g}$ of material was obtained.

Samples of the initial and the aged precipitates were examined by SEM and by $x$-ray diffraction.

\section{c. Preparation of the Oxide Powder}

A thermal decomposition study of $\mathrm{Ce}_{2}\left(\mathrm{CO}_{3}\right)_{3} \cdot 8 \mathrm{H}_{2} \mathrm{O}$ by Head and Holley indicated that the water of hydration was driven off below $200^{\circ} \mathrm{C}$, and that the anhydrous carbonate decomposed below $600{ }^{\circ} \mathrm{C}$. X-ray diffraction of a sample calcined at $620^{\circ} \mathrm{C}$ showed that only broad fluorite-structure peaks were present so that initial calcination of the powder was carried out at this temperature. The yield of oxide powder, when corrected for an LOI of 2.65 percent, was $655 \mathrm{~g}$, which amounted to a recovery of 68-70 percent of the oxides.

Samples of the oxide powder were calcined further for one hour at 700,800 and $900{ }^{\circ} \mathrm{C}$ and were examined by $\mathrm{x}$-ray diffraction and by SEM. Some TS specimens were prepared from these powders.

\section{d. Preparation and Characterization of Ceramic Specimens}

About $350 \mathrm{~g}$ of the calcined powder was formed into a billet without binder, isostatically pressed and then hot-pressed in an alumina die for 30 minutes at $1350{ }^{\circ} \mathrm{C}$ with an applied load of $28 \mathrm{MPa}$. The billet exhibited excessive shrinkage during hot-pressing and broke into several large pieces.

Specimens were cut from the billet for electrical studies, to be reported on elsewhere [31], and for examination by cptical microscopy, SEM and $x$-ray diffraction. Densities of the polished specimens were obtained from mass and size measurements. An unetched specimen was examined by electron micro-probe [32] for possible chloride contamina- 

tion at the grain boundaries. Fracture surfaces from several smaller pieces were examined by SEM and by STEM [33], both with analytical x-ray capabilities.

$X$-ray fluorescence [34] was used to measure the $C e$ and $Y$ content of the HP material. Samples of the crushed and ground material were fused in lithium tetraborate to form borate-glass disks. Standard samples containing known amounts of $C e$ and $Y$ were prepared in a similar manner.

Estimates of the impurity concentrations were obtained by semiquantitative spectrochemical analysis.

A small amount of the billet was ground to a fine powder and mixed with a smal1 portion of tungsten powder as a reference for a precise determination of the lattice constant [35]. A vertical, computerautomated $x$-ray diffractometer, with computer analysis of the count rate, was used for these measurements. $\mathrm{Ni}$-filtered CuKa radiation was used, with the x-ray tube operated at $40 \mathrm{KV}$ and $30 \mathrm{~mA}$. Since the $\mathrm{Ka}_{7}$ and $K \alpha_{2}$ diffraction peaks were well-resolved for $2 \theta>75^{\circ}$, only the midchord positions of the $K_{\alpha} 1(\lambda=1.540498 \AA)$ peaks from $75^{\circ}$ to $150^{\circ}$ were determined. The observed midchord positions were corrected using the simultaneously-determined midchord values for tungsten; the lattice constant of tungsten is $0.316524 \mathrm{~nm}, 0.000004 \mathrm{~nm}$ standard deviation [36]. The computed lattice constants were corrected for absorption by the Nelson-Riley method $[37,38]$.

Some specimens were prepared by forming them with a pellet press, isostatically pressing to $69 \mathrm{MPa}$ to produce a uniform and larger green density and thermally sintering at about $1520^{\circ} \mathrm{C}$ for one day. Bulk densities were measured by an Archimedes technique with mercury as the buoyant medium. 


\section{Results and Discussion}

\section{a. Composition and Crystal Structure of the Precipitate}

If the precipitate is assumed to have the general composition

$$
\operatorname{Ln}\left(\mathrm{CO}_{3}\right)_{\alpha}(\mathrm{OH})_{\beta} \cdot \mathrm{nH}_{2} \mathrm{O}
$$

where $\operatorname{Ln}=\mathrm{Ce}(\mathrm{III}), Y$ and

$$
2 \alpha+\beta=3 \text { (electroneutrality), }
$$

the ranges of $\alpha, \beta$ and $n$ can be estimated from the weights of the precipitate, $880 \mathrm{~g}$, and of the oxide, $655 \mathrm{~g}$, obtained by calcining the precipitate. In setting up the material balance equation which constrains $\alpha, \beta$ and $n$, we further assumed: (1) that the amounts of $C e$ and $y$ are the same for the precipitate and for the resulting oxide, (2) that calcination of the precipitate converts all of the $\mathrm{Ce}$ to $\mathrm{CeO}_{2}$ and all of the $\mathrm{Y}$ to $\mathrm{Y}_{2} \mathrm{O}_{3}$, and (3) that $\mathrm{CO}_{2}$ and $\mathrm{H}_{2} \mathrm{O}$ are the gaseous products evolved during the calcination. The Ce-Y composition of the oxide is reported in Section e. below. The electroneutrality condition and material balance equation can be solved to find $\alpha$ and $\beta$ in terms of $n$; thus,

$$
\begin{aligned}
& \alpha=2.02-0.69 n \\
& \beta=-1.03+1.39 n ;
\end{aligned}
$$

$\alpha$ and $\beta$ have physically meaningful values simultaneously only when

$$
0.74<n<2.91 \quad .
$$

The $x$-ray diffraction results for the precipitates in Table 2 show that, apart from some improvements in intensities and resolution and the appearance of a few additional lines, the initial precipitate and the aged precipitate had essentially the same phases. Differences in the $d$ values reflect difficulties in locating the centroid positions of rather 
broad diffraction maxima. Only a few of the d-values can be assigned to a previously identified material, hydroxyl-bastnaesite [39]. Although this assignment supports our estimated composition, it is inconclusive due to the remaining large number of unidentified lines, some of which are stronger than the lines tentatively assigned to hydroxyl-bastnaesite. b. Grain Size and Particle Size in the Oxide Powder

Calcination of the precipitate at temperatures in excess of $600{ }^{\circ} \mathrm{C}$ replaced the crystalline structure of the precipitate with the fluorite structure of $\mathrm{CeO}_{2}$, as shown by the results given in Table 2 for a calcination at $620^{\circ} \mathrm{C}$. The diffraction maxima were generally weak and very broad, and only the maxima at low angles were observed.

Estimates of crystallite size were made from the broadened diffraction maxima for powders calcined between 620 and $900{ }^{\circ} \mathrm{C}$. The measured peak widths, $B_{1 / 2}$, at half-maximum intensity for the (111), (200), (220) and (311) reflections were corrected to peak widihs, $\beta_{1 / 2}$, due solely to crystallite size broadening, first for instrumental broadening by means of the curve for "Low-angle reflections" in Fig. 9-9 of Ref. [40]. and then for $\mathrm{Ka}_{7} \alpha_{2}$ doublet broadening using curve $E$ in Fig. 9-8 of the same text. A powder sample obtained from the HP YDC, see Section $f$. , which had sharp diffraction maxima was used as a reference in making these two corrections.

The Scherrer [26] equation in the form

$$
L_{h k 1}=0.89 \lambda / \beta_{1 / 2}(h k 1) \cos \theta,
$$

see eq. (9-106) of [40], was used to obtain the effective crystallite dimension $L_{h k l}$ which are given in Table 3. As Stokes and Wilson [42] showed, $L_{h k l}$ can be considered to be a ratio,

$$
L_{h k T}=\left\langle T^{2}\right\rangle /\langle T\rangle,
$$


Table 2. X-Ray Diffraction Results (CuKa, $g=1.54178 \AA$ ).

Precipitate

$$
\text { Initial }
$$

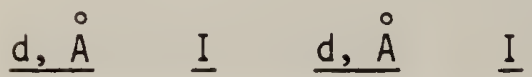

$1.51 ?$

1.59 ?

$1.68 ?$

$1.73 ?$

1.825 VW

1.854 VW $1.855 \quad W$

$1.90 \mathrm{~b} ? \quad 1.90 \mathrm{~b} \quad \mathrm{WW}$

$1.91 \mathrm{~b}$ ?

$1.92 \mathrm{~b} \quad ? \quad 1.92 \mathrm{~b} \quad \mathrm{WW}^{*}$

1.955 VW $1.951 \quad W$

2.005 VW $2.008 \quad W-M$

$2.011 W$

$$
\begin{array}{ll}
2.02 & ? \\
2.03 b & V W \\
2.05 b & V W^{*}
\end{array}
$$

$2.07 V W \quad 2.070^{\circ} W$

$2.073 W-M$

$2.073 \quad W-M^{*}$

2.09 ?

2.11 ?

$2.12 b \quad V W$

$2.14 b \quad V W \quad 2.14 b \quad V W$

$2.16 b \quad V W \quad 2.16 b \quad V W$

$2.348 \quad M \quad 2.348 \quad M$

$\begin{array}{llll}2.431 & 2.429 & W \\ & 2.47\end{array}$

$2.506 \quad W \quad 2.501 \quad W^{*}$

2.67 ?

$2.65 \mathrm{~b} \quad \mathrm{~W}$

$2.78 \quad ?$

$2.88 \mathrm{~b} \quad \mathrm{VW}$

$2.90 b \quad W \quad 2.90 b \quad V W$

$2.914 W$

$2.957 \quad M \quad 2.952 \quad M *$

$$
\text { Oxide, } 620{ }^{\circ} \mathrm{C}
$$

$\underline{\mathrm{d}, \AA} \quad \underline{\mathrm{A}} \underline{\mathrm{hk}}$

1.36 VW 400

1.56 VW 222

$1.63 W-M \quad 311$

$1.912 M \quad 220$

\section{$2.703 \quad M \quad 200$}




\section{Precipitate}

\begin{tabular}{|c|c|c|c|}
\hline \multicolumn{2}{|c|}{ Initial } & \multicolumn{2}{|c|}{ Aged } \\
\hline$\underline{d}, \AA$ & $\underline{I}$ & $\underline{d}, \AA$ & I \\
\hline $3.37 b$ & M & $\begin{array}{l}3.36 b \\
3.55 b\end{array}$ & $\begin{array}{l}M \\
V W\end{array}$ \\
\hline $3.58 \mathrm{~b}$ & W & $3.58 b$ & $V W^{*}$ \\
\hline 3.601 & W & 3.601 & W \\
\hline $3.695 \mathrm{~b}$ & $W-M$ & $3.695 \mathrm{~b}$ & M \\
\hline 3.720 & M & $\begin{array}{l}3.717 \\
4.03\end{array}$ & $\begin{array}{l}\text { M-S } \\
?\end{array}$ \\
\hline $4.28 b$ & $W-M$ & $4.28 \mathrm{~b}$ & M \\
\hline 4.324 & $s$ & $\begin{array}{l}4.316 \\
4.89 b\end{array}$ & $\begin{array}{l}S \\
\text { VW }\end{array}$ \\
\hline 4.912 & W & 4.917 & W \\
\hline 4.969 & W & 4.950 & $W^{*}$ \\
\hline 5.560 & $W-M$ & 5.553 & M \\
\hline
\end{tabular}

Abbreviations: $b=$ broad peak; ? = peak uncertain; $V W=$ very weak; $W=$ weak; $W-M=$ weak to medium; $M=$ medium; $M-S=$ medium to strong; $S=$ strong. The "** indicates that the peak corresponds to a structural analog of hydroxyl-bastnaesite. 
of volume averages of the crystallite dimension $T$ normal to the reflecting planes. These estimates assume the absence of strain broadening and, therefore, may be considered to underestimate the crystallite size. From 620 to $800{ }^{\circ} \mathrm{C}$ the crystallites appear to be somewhat larger in the (hoo) than in other directions (see Table 3 below). The somewhat smaller values of $L_{h k l}$ in the other directions suggest that the particles may have had irregular prismatic shapes. Calcining the $620^{\circ} \mathrm{C}$ powder at $700{ }^{\circ} \mathrm{C}$ for one hour had little additional affect on the crystallite size. Calcining the $620^{\circ} \mathrm{C}$ powder at $800{ }^{\circ} \mathrm{C}$ for one hour, however, appears to have induced a doubling of the crystallite dimensions. Calcining at $900{ }^{\circ} \mathrm{C}$ appears to have produced no further coarsening in the [h00] directions but to have produced growth in the other directions so that the crystallites appeared more nearly rounded.

Chord-sizing of a sample of the powder calcined at $620^{\circ} \mathrm{C}$ with an image analyzer yielded a particle sịe distribution characterized by the following statistical quantities:

$\begin{array}{ll}\text { mean diameter } & 1.2 \mu \mathrm{m} \\ \text { standard deviation } & 1.2 \mu \mathrm{m} \\ \text { coef. of skewness } & 0.7 \\ \text { kurtosis } & 5 .\end{array}$

Since the smallest size fraction contained a preponderance of the particles, and since there appeared to be particles just below the detection threshold of the instrument, $0.25 \mu \mathrm{m}$, which could not be distinguished for the purpose of counting and sizing, the measured particle size distribution very likely was biased toward the larger size particles. Comparing the particle size and crystallite size, it appears that an average particle may have contained on the order of $10^{5}$ crystallites. 
Table 3. Effective Crystallite Dimensions, $L_{h k}$

\begin{tabular}{|c|c|c|c|c|}
\hline Calcination & (111) & (200) & (220) & (311) \\
\hline Temp., ${ }^{\circ} \mathrm{C}$ & $\mathrm{nm}$ & $\mathrm{nm}$ & $\mathrm{nm}$ & $\mathrm{nm}$ \\
\hline 620 & 17 & 24 & 18.5 & 18.5 \\
\hline 700 & 23 & 25 & 23 & 18.5 \\
\hline 800 & 34 & 51 & 30 & 34 \\
\hline 900 & 37 & 51 & 52 & 64 \\
\hline
\end{tabular}




\section{c. Microstructure of the Precipitate and Oxide Powder}

The initial precipitate exhibited a lamellar structure, Fig. 3a, with many platelets several micrometers across. Aging the precipitate disrupted this microstructure and produced many irregular shapes ranging in size from a few micrometers to several tens of micrometers across. Figure $3 \mathrm{~b}$ is a micrograph of a portion of a large agglomerated particle from the aged precipitate.

Calcining the precipitate produced a powder with particles which did not differ significantly in appearance, see Fig. $3 c$, from those of the aged precipitate. This powder was very friable.

\section{d. Density and Some General Features of the HP Ceramics}

The bulk density of specimens cut from the HP YDC was $6.96 \mathrm{~kg} / \mathrm{m}^{3}$, with a 95 percent confidence limit of $\pm 0.04 \mathrm{~kg} / \mathrm{m}^{3}$. From the composition, Section e., and the lattice constant, Section f., the theoretical density was calculated to be $7.003 \pm 0.008 \mathrm{~kg} / \mathrm{m}^{3}$. Thus, the bulk density was $99.4 \pm 0.6$ percent of TO. Thermal sintering resulted in specimens with densities in the range of 92 to 98 percent of TO.

The overall appearance of the HP material was that of a beigecolored ceramic, with a glassy luster and conchoidal fracture. Pieces about a millimeter thick were translucent; sections 40-50 $\mu \mathrm{m}$ thick were transparent. The material was resistant to etching with strong acid and very resistant to erosion by an ion beam [43]--very long thinning times were required to prepare a HP sample for STEM analysis.

e. Composition of the HP Ceramic

The HP YOC was found to consist of 91.4 mol percent $\mathrm{CeO}_{2}$ and 8.6 mol percent $\mathrm{YO}_{1.5}$, with a 95 percent confidence limit of $\pm 0.3 \mathrm{~mol}$ percent. 

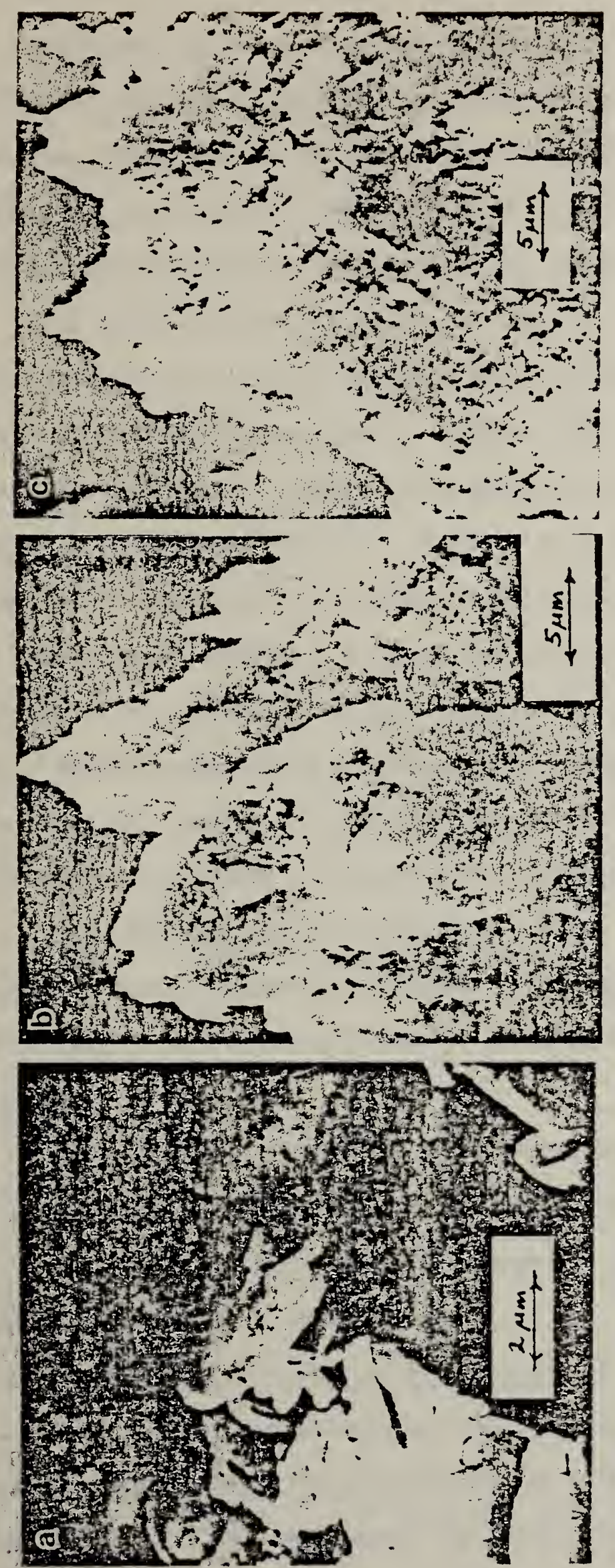

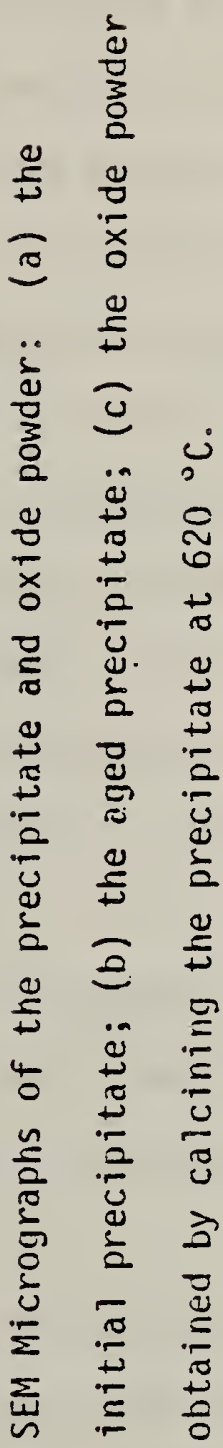



Semiquantitative spectrochemical analysis of the HP YDC material indicated that the Al impurity had increased, but that the other impurities either had not changed significantly or had been reduced. A sample was analyzed by FE/AA analysis to obtain a more sensitive and precise determination of the $\mathrm{A} T, \mathrm{Na}$ and $\mathrm{K}$ impurities in the HP ceramic.

The FE/AA analysis, third row of Table 1 , indicated that Al-content had increased by up to 100 percent, the $\mathrm{Na}$-content by 300 percent and the K-content had not increased. A larger increase in Al content was noted for a HP sample prepared from mechanically blended $\mathrm{CeO}_{2}-\mathrm{Y}_{2} \mathrm{O}_{3}$ powder, second row of Table 1. The alumina die used for the hotpressings is suspected to have been the source of the Al contamination in these two HP ceramics. A thin brown reaction zone was present at the surface of the billets after hot-pressing, and some brown flecks were found beneath the surface of the ceramics suggesting that grains of the "lubricating" alumina were pressed into the billet. The Na contamination probably resulted from the chemical processing.

Although tests of the supernatant liquids from the rinsing of the precipitate did not show the presence of $\mathrm{Cl}^{-}$by the third rinse, we still considered it possible that $\mathrm{Cl}^{-}$-ions were adsorbed by the precipitate.

Scans of HP YDC samples by electron microprobe and analytical STEM did not detect $\mathrm{Cl}^{-}$. However, neither technique apparently was capable of examining solely the narrow grain boundary regions where chlorides or oxychlorides may have segregated.

f. Crystal Structure and Lattice Constant of the HP Ceramic $X$-ray diffraction showed that the HP ceramic was a single phase material having the fluorite structure and with a lattice constant of $0.541088 \mathrm{~nm}, 7 \times 10^{-6} \mathrm{~nm}$ standard deviation. Electron diffraction [43] 
from individual grains, using smallest available selected area aperture, gave patterns corresponding to a fluorite-type (FCC) lattice. No diffuse or extra reflections were observed.

Our determinations of the lattice constant is compared in Table 4 with the results of other investigators [44-49], all of whom used photographic methods, in most cases the Debye-Scherrer method. With the exception of the earliest measurement by McCullough and Britton [44-45], all of the previous measurements gave values which were lower than our diffractometer result. Only the Debye-Scherrer measurements by Bevan, et a1. [47] and by Anderson and Wuensch [48] approach the precision of our diffractometer measurement.

With the exception of results of McCullough and Britton the cited values of the lattice constant in Table 4 were interpolated to a composition of 8.6 mol percent $\mathrm{YO}_{1.5}$ from the lattice constant vs. composition data reported by the respective investigators. McCullough and Britton obtained the same value for the lattice constants of pure ceria and ceria doped with $9.99 \mathrm{~mol}$ percent $\mathrm{YO}_{1.5}$. To indicate the precision of the respective measurements, the uncertainties cited in the table are those given by the respective authors, with the exception of Adham [49] where the uncertainty is the standard deviation of the fit; thus, these uncertainties do not contain any additional error due to the interpolation.

There are important differences between our determination of the lattice constant and the precise Debye-Scherrer determinations by Bevan, et al. and by Anderson and Wuensch with respect to $x$-ray technique, material preparation and material characterization, as well as possible errors resulting from the interpolation of the previous results to our composition. Each of these differences may serve wholly, or in 
Table 4. Determinations of the Lattice Constant of $\mathrm{CeO}_{2}: \mathrm{YO}_{1.5}$

\begin{tabular}{|c|c|c|c|}
\hline Investigators & $\begin{array}{l}\text { Preparative Method } \\
\text { and X-ray Diffrac- } \\
\text { tion Method } \\
\end{array}$ & $\begin{array}{l}\text { Composition, } \\
\text { mol \% } \mathrm{YO}_{1.5} \\
\end{array}$ & $\begin{array}{l}\text { Lattice } \\
\text { Constant, } \\
\mathrm{nm} \\
\end{array}$ \\
\hline $\begin{array}{l}\text { McCullough \& } \\
\text { Britton }\end{array}$ & $\begin{array}{l}\text { Copptn. of hydroxides; } \\
\text { ignition at } 1100- \\
1200{ }^{\circ} \mathrm{C} \text {. Powder dif- } \\
\text { fraction photography. }\end{array}$ & 9.99 & $\begin{array}{l}0.5411 \\
\pm .0002\end{array}$ \\
\hline $\begin{array}{l}\text { Brauer \& } \\
\text { Gradinger }\end{array}$ & $\begin{array}{l}\text { Copptn. of oxalates; } \\
\text { ignition at } 1400{ }^{\circ} \mathrm{C} \text {. } \\
\text { Debye-Scherrer. }\end{array}$ & 8.6 & $\begin{array}{l}0.5409^{a, b} \\
\pm .0001\end{array}$ \\
\hline $\begin{array}{l}\text { Bevan, Barker, } \\
\text { Martin \& Parks }\end{array}$ & $\begin{array}{l}\text { Both copptn. and mech. } \\
\text { mixed powders; pressed } \\
\text { pellets sintered at } \\
1600{ }^{\circ} \mathrm{C} \text { for four or } \\
\text { more days. Debye- } \\
\text { Scherrer. }\end{array}$ & 8.6 & $\begin{array}{l}0.54091^{C} \\
\pm .00001\end{array}$ \\
\hline $\begin{array}{l}\text { Anderson \& } \\
\text { Wuensch }\end{array}$ & $\begin{array}{l}\text { Mech. mixed powders; } \\
\text { pressed samples sinter- } \\
\text { ed for } 100 \mathrm{hr} \text {. at } \\
1750{ }^{\circ} \mathrm{C} \text {, equilibrated } \\
\text { for } 50 \text { days at } 800{ }^{\circ} \mathrm{C} \text {. } \\
\text { Debye-Scherrer. }\end{array}$ & 8.6 & $\begin{array}{l}0.54098^{b} \\
\pm .00003\end{array}$ \\
\hline Adham & $\begin{array}{l}\text { Copptn. of oxalates; } \\
\text { calcined at } 1000{ }^{\circ} \mathrm{C} ; \\
\text { pressed specimens sin- } \\
\text { tered at } 1600{ }^{\circ} \mathrm{C} \text {. } \\
\text { Debye-Scherrer. }\end{array}$ & 8.6 & $\begin{array}{l}0.5410^{d} \\
\pm .0001\end{array}$ \\
\hline This work & $\begin{array}{l}\text { Copptn. of carbonates; } \\
\text { calcined at } 620^{\circ} \mathrm{C} \text {; } \\
\text { oxide billet hot-pressed. } \\
\text { Automated powder dif- } \\
\text { fractometer. }\end{array}$ & 8.6 & $\begin{array}{l}0.541088 \\
\pm .000007\end{array}$ \\
\hline
\end{tabular}

a. Lattice constant adjusted to $\lambda\left(\mathrm{CuKa}_{1}\right)=1.54051 \AA$.

b. Lattice constant interpolated to $8.6 \mathrm{~mol}$ percent $\mathrm{YO}_{1.5}$ by fitting a quadratic function to lattice constant-concentration data for the fluorite structure region.

c. Lattice constant calculated from eq. for $0-10$ percent $Y_{1} 0_{1.5}$ (Ref. [4], p. 459).

d. Lattice constant interpolated to $8.6 \mathrm{~mol}^{1}$ percent $\mathrm{YO}_{1.5}$ by least squares fit of lattice constant-composition data. 
part, to account for the discrepancy between these values for the lattice constant. A satisfactory explanation of the discrepancy will require measurements on the same material by the two techniques.

g. Microstructure of the H.P Ceramic

Micrographs of fracture surfaces of the HP material are shown in Figs. 4a and b. Figure $4 a$ shows a fracture surface, which formed during hot-pressing; Fig. $4 b$ shows one formed by mechanically fracturing the material. Both surfaces were chemically etched with a solution of nitric acid-hydrofiuoric acid (nitric acid: hydrofiuoric acid: water $90: 10: 100$ ) for about 20 minutes with ultrasonic stirring. Figure $4 c$ is a bright field electron micrograph [43] of an ion-beam thinned specimen.

A very small amount of porosity is evident in these three micrographs. Figures $4 a$ and $c$ reveal that most of the porosity is along the grain boundaries and not within the grains. The grains shown in Fig. 4 a apcear to be about 2-4 $4 \mathrm{~m}$ in size, whereas those shown in $4 \mathrm{c}$ are on the order of one um, or perhaps less. It is not clear whether this difference is due to more than variation resulting from samoling. In both cases the grains appear to be equiaxed.

The surface formed during hot-pressing shows weil-etched grain boundaries, whereas the mechanicaliy fractured surfacs shows very little evidence of etcining. This difference may have resulted either from thermal etching of the former surface or from exsolution of a more soluble phase to the fracture surface during hot-pressing.

\section{Summary}

Homogeneous coprecioitation of $C e$ and $y$ by the decompositicn of the trichioroacetate can be used to sroduce a fine precipitate as a precursor for a sinterable oxide powder. The precioitate obtained in this work apoarently wes a mixture of hydrated carbonate, hydroxy-carbonate 

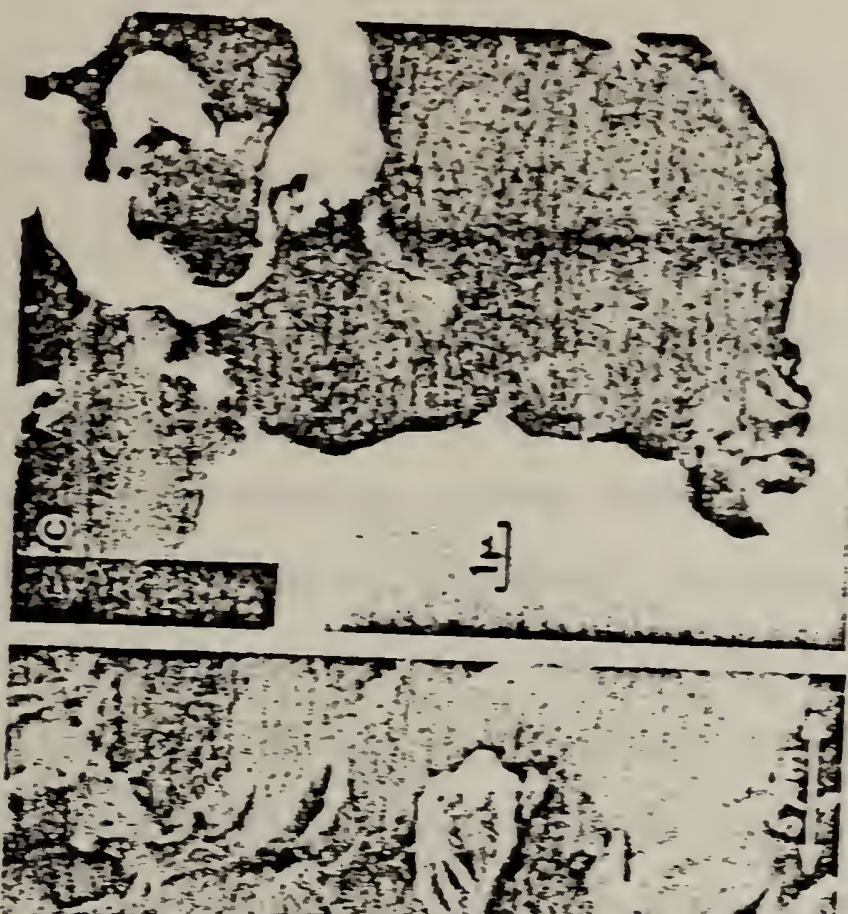

a

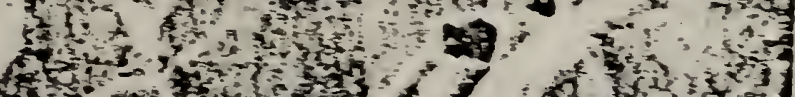

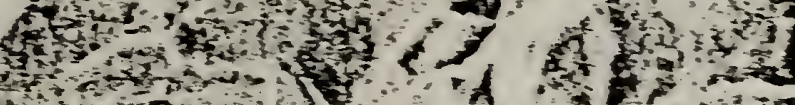

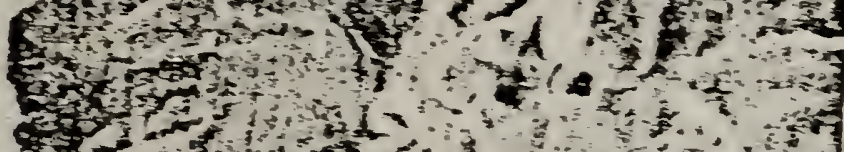

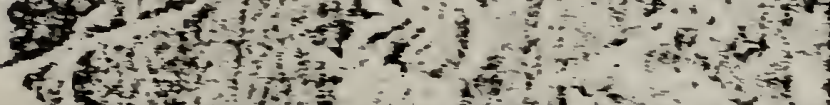

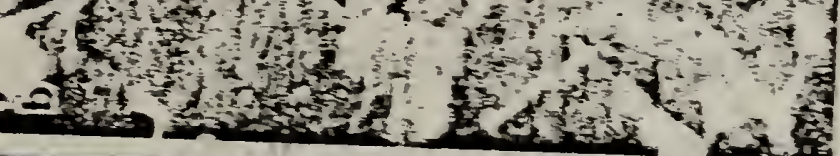

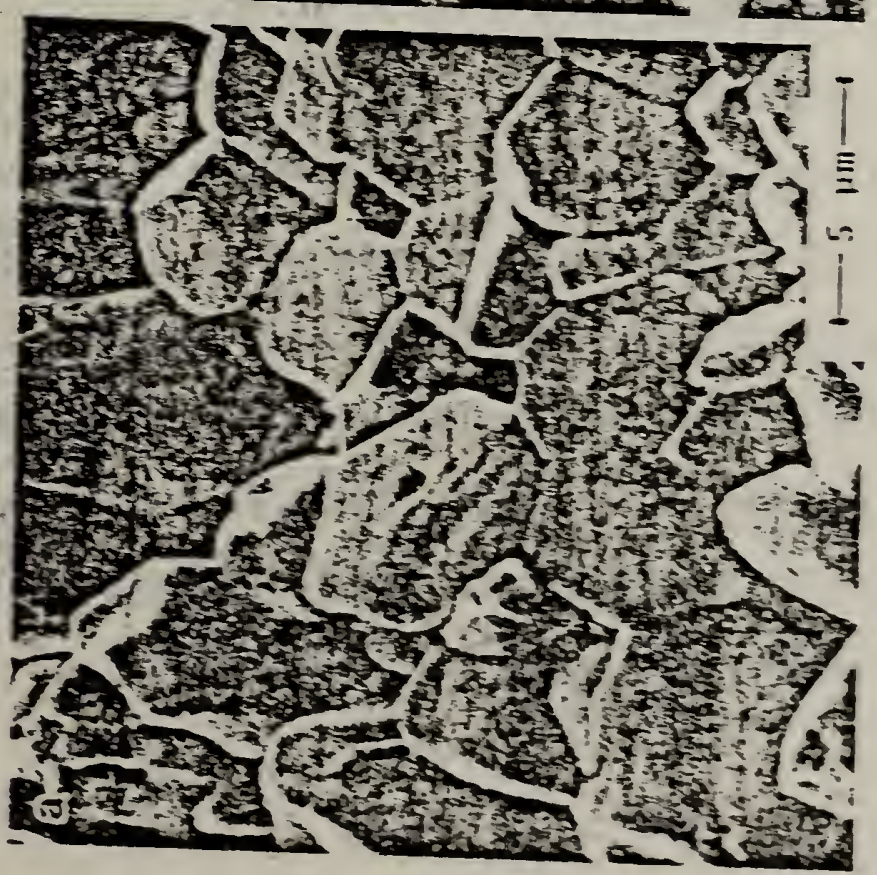

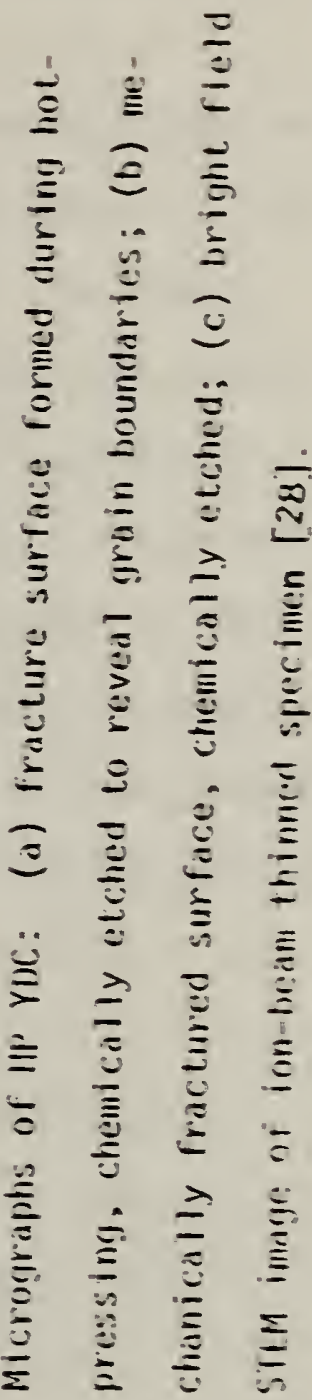



and hydroxide rather than a simple carbonate. The process suffers from the disadvantage that it is not quantitative and that there was some loss of $Y$ relative to the Ce. However, the sharpness of the $X$-ray diffraction peaks indicate that the resulting ceramic was very homogeneous so that significant fractionation of the $C e$ and $Y$ during the process does not appeared to have occurred.

The oxide powder was sintered by hot-pressing under relatively mild conditions--applied load of $28 \mathrm{MPa}$ and $1350{ }^{\circ} \mathrm{C}$ for 30 minutes-- to yield a material with a density of $99.4 \pm 0.6$ percent of TD. The ceramic appeared to consist of rather equiaxed grains, with dimensions in the range 1-4 $\mu \mathrm{m}$, with the porosity mainly along the grain boundaries.

The billet cracked during hot-pressing, possibly as a result of excessive shrinkage; however, this difficulty may be avoided by calcining the oxide powder at a higher temperature prior to the sintering stage. Also, there was some evidence of contamination of the YDC by $A 1$, which most likely came from the $\mathrm{Al}_{2} \mathrm{O}_{3}$ die used in the hot-pressing, and by $\mathrm{Na}$, which probably originated from the chemical processing.

\section{Acknowledgments}

The characterization of our ceria-yttria ceramic was greatly assisted by contributions of a number of individuals: J. Drennan, June M. Epp, C. R. Hubbard, D. E. Newbury and P. A. Pella. Their specific contributions are referenced in the paper. Finally, L. P. Domingues of Trans Tech, Inc. was an active collaborator and will be a coauthor on publications on this work.

We also gratefully acknowledge the financial participation of the Fuel Cel1 Program of the Department of Energy in support of this work. 


\subsubsection{Electrical Properties of $\mathrm{Y}$-Doped $\mathrm{CeO}_{2}$ : Comparison of ac and dc Measurements}

\section{Introduction}

The study of electrical transport processes in real, polycrystalline solids can be complicated by the presence of grain boundaries, porosity, second phases, and cther forms of inhomogeneity within the bulk of the specimen. Where the conductivity is anisotropic, a distribution in orientation of the crystal grains will also act as a source of inhomogeneities. In general, electrical inhomogeneities give rise to depolarizing fields at a local level within the material and as a result the observed dc conductivities, measured with the classical 4-probe technique, do not correspond to the intrinsic conductivity of the crystalline material. On the other hand, it is the latter, as measured with a single crystal devoid of such inhomogeneities, that is the proper subject of theoretical treatments of lattice conduction.

The frequency dependence of the electrical transport properties contains information on the separate contributions made by intrinsic transport and by the various inhomogeneities. (For a recent review, see Bottelberghs [50]). In this paper we present impedance data for $Y$-doped $\mathrm{CeO}_{2}$ ceramics prepared by several techniques, and examine the influence of the preparation technique upon, especially, the inhomogeneity impedance. We also point out the inadequacy of the standard 4-probe dc technique for measuring conductivity where a significant inhomogeneity contribution exists, and the need for measurements over a sufficient range of frequencies rather than at a single "high" frequency, as is often reported.

\section{a. Equivalent Circuit}

Bauerie [51] first suggested that grain boundaries and other inhomogeneities gave rise to contributions to the impedance of an elec- 
trical conductor, and proposed to represent these elements in an equivalent circuit as a parallel resistance-capacitance network, in series with a resistance representing the intrinsic resistance of the grain interiors. In our work we have found that the inhomogeneity impedance, $Z_{i}$, often appears better represented not as a single $R C$ network, but rather as a series ensemble with a distribution of time constants. Following Schouler, et a1. [52] we find we can represent the experimental data rather well if we use a Cole-Cole [53] distribution. The equivalent circuit we therefore use is shown in Fig. 5. The circuit elements and parameters are as follows: $C_{g}$ is the geometric capacitance; $R_{L}$ is the intrinsic or lattice resistance contributed by the grain interiors; $z_{i}$ is the impedance arising from the inhomogeneities, such as grain boundaries, second phase particles, or pores; and $z_{e l}$ is the electrode impedance. Our data were taken at sufficiently high frequencies that $z_{e l}$ did not contribute to the impedance in any important way, and $z_{e l}$ will be considered below only incidentally. $z_{i}$ is represented by

$$
z_{i}=\frac{R_{i}}{1+(j \omega \tau)^{n}},
$$

where $R_{i}$ is the inhomogeneity resistance, $n$ is a parameter between 0 and 1 , expressing the width of the Cole-Cole distribution of time constants (for a single $R-C$ network $n=1$ ), $\tau$ is the most probable time constant in the distribution, and $\omega$ is the circular frequency. An equivalent capacitance, $c_{i}$, can be defined by

$$
\tau=R_{i} C_{i}
$$




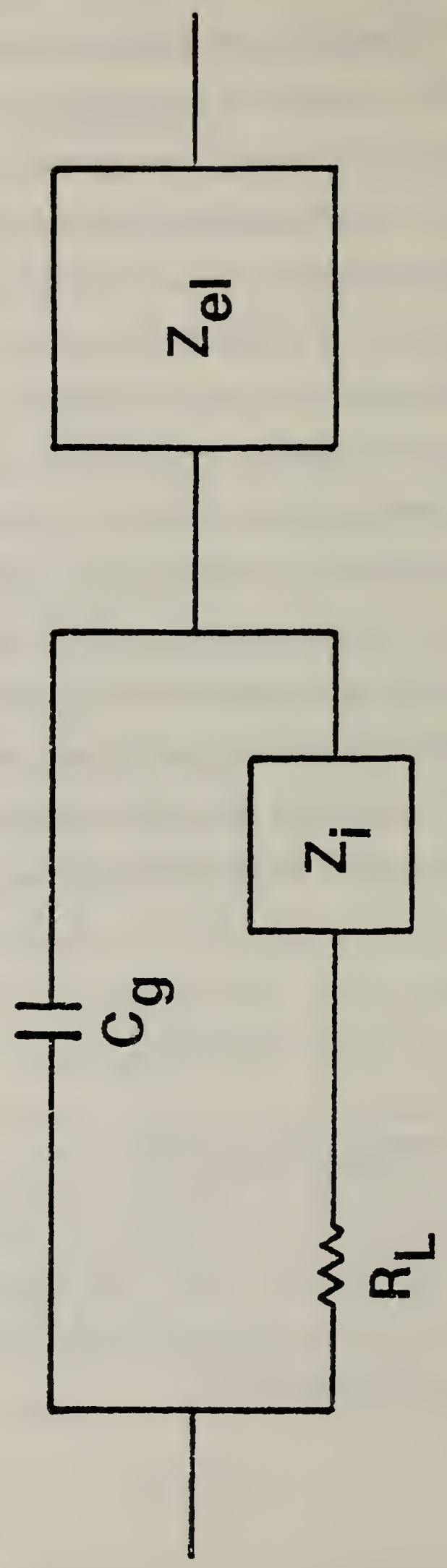

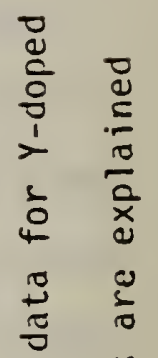

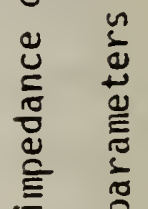

른 흥

嵌

过

के ए

일

ปั

$\stackrel{\Xi}{=}$

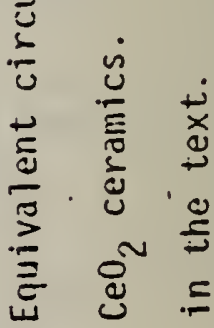

$\ddot{~}$ 
This same equivalent circuit, often without invoking a distribution of time constants, has been used in a number of studies. Powers and Mitoff [54] analyzed impedance data for polycrystalline sodium beta alumina and found an inhomogeneity contribution that they attributed to grain boundaries and that appeared to call for a distribution of time constants. Hooper [55] compared impedance data for single and polycrystalline sodium beta alumina and found the inhomogeneity contribution only with the polycrystalline material. Again, although not considered in Hooper's study, the data suggest a distribution of time constants for the inhomogeneity contribution.

Raistrick et al. [56], on the other hand, represented very similar data on lithium silicates and aluminosilicates by a different equivalent circuit. In their work the grain boundary effects were represented by a cirçuit element placed parallel to the intrinsic resistance and geometric capacitance. The admittance of this grain boundary element was taken as frequency dependent according to $\gamma^{*}=A \omega^{\alpha}+i B \omega^{\alpha}$. We have shown previously [57] that the electrical behavior of the equivalent circuit of Raistrick et al. [56] can be essentially the same as that of the circuit in Fig. 5, so that the choice is not necessarily dictated by the data.

\section{b. Source of Inhomogeneity Impedance}

The appearance of such an inhomogeneity contribution to the impedance in polycrystalline specimens is often attributed to grain boundaries, and indeed, as in the work of Hooper [55] above there is good reason to suppose that grain boundaries are a likely cause. However, Armstrong et a1. [58] pointed out that in the case of an anisotropic material like sodium beta alumina a distribution in grain orientations will also give rise to such an effect. Also, the appearance of apparent 

inhomogeneity contributions in impedance data on single crystals suggest other important causes.

For instance, Levitskij et a1. [59,60] found what appear to be inhomogeneity contributions to the impedance of single crystals of $\mathrm{CaF}_{2}$ and $\mathrm{BaF}_{2}$. This contribution was sensitive to the oxygen activity in the atmosphere and probably arises from highly conducting surface layers produced by incorporation of oxygen ions on anion sites plus anion vacancies. The effects are similar to those noted and attributed to surface layers on oxidized fluorite crystals by Franklin et al. [61] and Johnson et a1. [62] some years ago and more recently by Wapenaar and Schoonman [63]. Van Alpen and Bell [64] also found an inhomogeneity contribution in the impedance of single crystals of $\mathrm{Li}_{3} \mathrm{~N}$, and suggested that dislocations and subgrain boundaries might be responsible.

Beekmans and Heyne [65] observed an inhomogeneity contribution in the impedance of $\mathrm{Ca}_{0.15} \mathrm{Zr}_{0.85}{ }^{0} 1.85$ ceramics which correlated with the presence of a second phase, rich in impurity $\mathrm{SiO}_{2}$, on the grain boundaries. Chu and Seitz [66] also observed a strong inhomogeneity contribution in $\mathrm{CaO}$-doped $\mathrm{ZrO}_{2}$, however without being able to detect the presence of second phases. They attributed the inhomogeneity impedance to grain boundaries. On the other hand, De Jonghe [67] has shown that the observed inhomogeneity contribution may reflect a mix of intrinsic and grain boundary properties, so that it may not be possible to interpret the experimental data simply in terms of separate intrinsic and grain boundary contributions.

Heterogeneous dielectrics, composed of discrete particles of a minority phase with conductivity and dielectric constant differing from those of the matrix in which the particles are embedded, have long been known to exhibit relaxations in the dielectric properties (MaxwellWagner effect). The existence of such a relaxation in the dielectric 
constant implies that a relaxation will also appear in the impedance. Van Beek [68] has treated this problem, for dilute heterogeneous systems, in a rather general way. His equations, when cast into the impedance representation, describe exactly the behavior of the equivalent circuit in Fig. 5. In particular, it can be shown that they lead to

$$
\frac{R_{i}}{R_{L}}=\frac{A_{a}(\varepsilon x-1)^{2}(1-p) p}{\left[(1-p)\left\{A_{a}(x-1)+1\right\}+x p\right]\left[A_{a}(1-p)(1-\varepsilon)+\varepsilon\right]^{2}}
$$

where $\varepsilon=\varepsilon_{1} / \varepsilon_{2}$ and $x=x_{2} / x_{1}$, and $\varepsilon_{1}, \varepsilon_{2}$ and $x_{1}, x_{2}$ are the dielectric constant and conductivity of the matrix, dispersed phase; $p$ is the volume fraction of the latter, and $A_{a}$ depends on the axial ratio a/b of the spheroidal particles, which are assumed identical and non-interacting. $A_{a}$ is given by:

prolate $a / b>1$

$A_{a}=\frac{1}{\left[(a / b)^{2}-1\right]}-1+\frac{(a / b)}{(a / b)^{2}-1} \ln (a / b)+\sqrt{ }(a / b)^{2}-1$

sphere $a / b=1$

$$
A_{a}=1 / 3
$$

oblate $a / b<1$

$$
A_{a}=\frac{1}{\left[1-(a / b)^{2}\right]} 1-\frac{(a / b)}{\sqrt{1}-(a / b)^{2}} \cos ^{-1}(a / b)
$$

\section{Experimental Details}

a. Specimen Preparation

Ceramic specimens of $\mathrm{Ce}_{1-x^{Y}} x \mathrm{O}_{2-x / 2}$, with $\mathrm{x}$ near 0.1 or 0.2 , were sintered from $\mathrm{Y}$-doped $\mathrm{CeO}_{2}$ powder prepared by several methods. "Mixed 
Oxide" specimens started with high-purity $\mathrm{Y}_{2} \mathrm{O}_{3}$ and $\mathrm{CeO}_{2}$ powders, which were mechanically mixed and calcined in air at temperatures around 1000$1200{ }^{\circ} \mathrm{C}$, isostatically pressed and fired in air at $\sim 1500{ }^{\circ} \mathrm{C}$ for about 16 hours. Densities measured by flotation in a dense but fluid fluorocarbon liquid ranged from 72 to 94 percent of theoretical. Bulk densities calculated from specimen masses and geometries were often lower than flotation densities, indicating considerable open porosity in some of the specimens. One specimen (HP8) was hot-pressed at $1350^{\circ} \mathrm{C}$ and $28 \mathrm{MPa}$ pressure for 45 minutes, with a resulting flotation density of 94 percent theoretical. However, both $x$-ray diffraction and microscopic examination showed incomplete reaction, with two phases present $\left(\mathrm{Y}_{2} \mathrm{O}_{3}\right.$ and fluorite, presumably a solid solution of $\mathrm{Y}_{2} \mathrm{O}_{3}$ in $\mathrm{CeO}_{2}$ ).

"Chemically prepared" specimens started with $\mathrm{Y}$-doped $\mathrm{CeO}_{2}$ powder prepared by homogenous precipitation of the mixed carbonate from trichloracetic acid solution, followed by calcination at 600-800 ${ }^{\circ} \mathrm{C}$ [69]. This powder was isostatically pressed and then hot-pressed at $1350{ }^{\circ} \mathrm{C}$ and $28 \mathrm{MPa}$ in air for 30 minutes. Densities (both flotation and bulk) exceeded 95 percent of theoretical. The x-ray diffraction spectrum exhibited only the fluorite structure, and the diffraction peaks were very sharp. The material was light brown in color and somewhat translucent. The grains were essentially equi-axed, with a rather uniform distribution in sizes in the 2-4 $\mu \mathrm{m}$ range. Details of this preparation and characterization of the resulting material will be given in a subsequent publication.

\section{b. Electrical Measurements}

The impedance was measured on either disks or flat square plates of about $2 \mathrm{~mm}$ thickness and $8-10 \mathrm{~mm}$ diameter or width. Electrodes were Pt or Au, sputtered onto the two large surfaces after polishing with $1 / 4 \mu \mathrm{m}$ 
diamond powder followed by a brief final polish with Linde B. * The electrode thickness required to maintain stability up to about $1000{ }^{\circ} \mathrm{C}$ was about $200 \mathrm{~nm}$. An HP-3570A network analyzer system was used to measure sample impedance from $50 \mathrm{~Hz}$ to $13 \mathrm{MHz}$.

Meaningful data could be obtained at temperatures from about $200{ }^{\circ} \mathrm{C}$ to about $800{ }^{\circ} \mathrm{C}$. Oxygen partial pressures were controlled in the range from about ten $\mathrm{Pa}$ to $0.02 \mathrm{MPa}\left(10^{-4}\right.$ to one atmosphere) by bleeding $\mathrm{O}_{2}$ into an argon stream, and were measured with an oxygen gauge downstream of the specimen.

The 4-probe dc measurements were performed on a bar-shaped specimen with dimensions of $1.7 \mathrm{~mm} \times 1.7 \mathrm{~mm} \times 13 \mathrm{~mm}$. The electrodes were $\mathrm{Pt}$ paste (fired at $1350^{\circ} \mathrm{C}$ ) with Pt leads. A high ac current was passed briefly through all electrodes in an attempt to render them porous. All contacts were ohmic for the currents used in the experiments (three to $300 \mu \mathrm{A} / \mathrm{cm}^{2}$ depending on sample resistance). A high impedance electrometer was used to measure the voltage drop across the potential probes. The temperature was measured with a pair of $\mathrm{Pt} / \mathrm{Pt}-10 \% \mathrm{Rh}$ thermocouples placed next to the specimen. Oxygen partial pressures were controlled and monitored as in the impedance experiments.

\section{Results}

The impedance is conveniently displayed in the complex plane, with the frequency as a parameter. Figures $6 a$ and $6 b$ show impedance plots for two contrasting specimens, all in the neighborhood of $250^{\circ} \mathrm{C}$. In Fig. 6a the specimen (B3) is a "mixed oxide" specimen, sintered in air

\footnotetext{
*Certa in commercial equipment, instruments, or materials are identified in this report in order to specify adequately the experimental procedure. In no case does such identification imply recommendation or endorsement by the National Bureau of Standards, nor does it imply that the material or equipment identified is necessarily the best available for the purpose.
} 

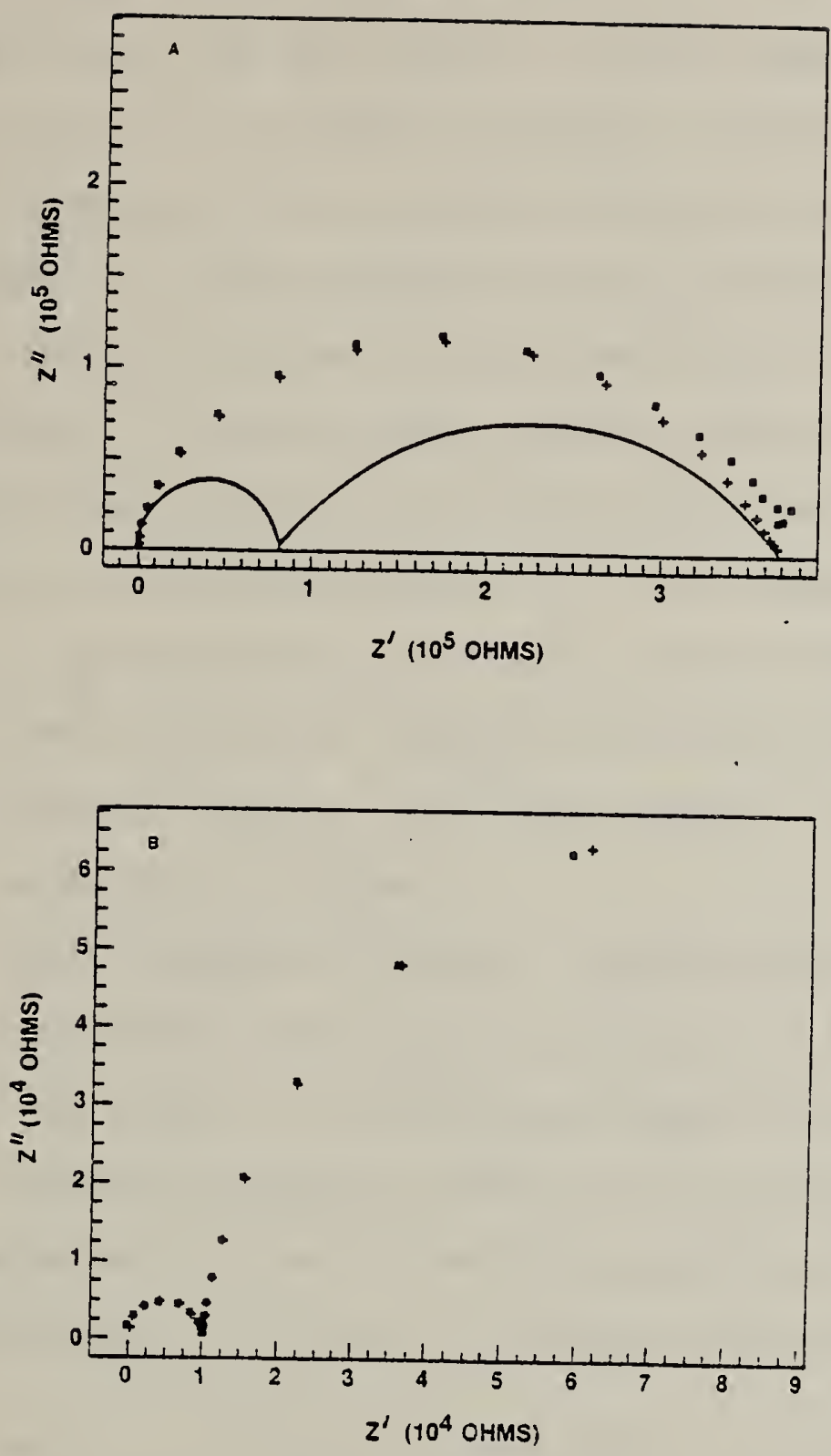

6: Impedance data in the complex plane for "mixed oxide" specimen 83 at $241{ }^{\circ} \mathrm{C}(\mathrm{a})$, and "chemically-prepared" specimen $\mathrm{B} 7$ at $251{ }^{\circ} \mathrm{C}$ (b). The observed data are indicated by squares, and the values calculated for the same frequencies from the equivalent circuit, as described in the text, are represented by pluses. The drawn arcs represent the behavior of $R_{L}$ in paraliel with $C_{g}$ (left-hand arc) and $z_{j}$ in series with $R_{L}$ (right-hand arc). 
at $1420{ }^{\circ} \mathrm{C}$ for 16 hours. In Fig. $6 \mathrm{~b}$ we show data for a "chemicallyprepared" specimen (B7), sintered in air at $1525{ }^{\circ} \mathrm{C}$ for 72 hours.

In both cases, the data points at the very highest frequencies approach the real axis essentialiy vertically, indicating that at these highest frequencies the data are controlled by the combination of $R_{L}$ (the intrinsic or lattice resistance) and $C_{g}$ (the geometric capacitance). With this as a clue, the equivalent circuit was fitted to the data as follows. Using the highest frequency data, the imaginary part (Z") of the complex impedance was plotted against the inverse circular frequency, $w$, and the slope taken as $\mathrm{C}_{\mathrm{g}}^{-1}$. The impedance data were then inverted to admittance and $\omega C_{g}$ subtracted from the imaginary part, $Y "$. The result was reinverted to impedance and the resulting values fitted with the Cole-Cole form [Eqn. (8)] of the impedance plus a constant, $R_{L}$, by a least-squares technique.

This technique works as follows: first the radius and center of the arc in the complex plane describing the data are found by minimizing the sum of the squares of the differences between the radius and the distances from the experimental points to the arc center. This establishes the values of $R_{L}$ and $Z_{i}$, and gives an estimate of $n$, but no information about $\tau$. The latter is estimated from the equation:

$$
\log (v / u)=\log \frac{\sqrt{ }\left(R_{L}+Z_{i}-Z^{\prime}\right)^{2}+Z^{\prime \prime}{ }^{2}}{\sqrt{ }\left(Z^{\prime}-R_{L}\right)^{2}+Z^{\prime \prime 2}}=n \log (\omega \tau) .
$$

$\log (v / u)$ is plotted against $\log \omega$, using observed values of $Z^{\prime}$ and $Z^{\prime \prime}$, and fitted near $\log (v / u)=0$ by least squares to a straight line, assuming no error in $\log \omega$. The estimate for $\tau$ is then

$$
\tau=\omega_{0}^{-1}
$$


where $\omega_{0}$ is the value of $\omega$ for which the fitted line crossed the line $\log (v / u)=0$. The slope of the fitted line gives a second estimate for $n$. Where this differs appreciably from the first estimate, the mean of the two is taken.

To refine these values for the parameters in the equivalent circuit, a steepest-descents least-squares 5 -parameter fitting program is used, minimizing the sum of the squares of the distances, in the complex plane, of the data points from values calculated for the same frequencies. In practice it is usually found that this refinement changes the parameters very little.

The calculated values are displayed in Figs. $6 a$ and $6 b$ by pluses. The figure also displays, in the form of solid arcs, the impedance plot for the parallel $R_{L} C_{g}$ network (left-hand arc) and for the series $R_{L}-Z_{j}$ network (right-hand arc). The fit of the calculated to the observed data suggests that the equivalent circuit of Fig. 5, with use of the Cole-Cole distribution of time constants for the inhomogeneity impedance, is a reasonable representation of the behavior of these materials, although it is not possible in every case to produce really good fits.

To assess these uncertainties, a set of eight measurements was made on one specimen (B3) in the temperature range from 220 to $340{ }^{\circ} \mathrm{C}$. It was found that the temperature dependences of $\left(R_{L} / T\right),\left(R_{i} / T\right)$, and $\tau$ all could be described by Arrhenius equations. A measure of precision for each was obtained by calculating the root mean square deviation (in percent) of the experimental value from the value calculated from the least square line in the Arrhenius plot, assuming no error in the temperature. These estimates of precision were all about 20-30 percent; a high value reflecting the imprecision attending computer fitting of oniy partially resolved relaxations. A measure of precision of $C_{g}$ was 
obtained from five independent measurements for each of two specimens with a total temperature span no more than $10{ }^{\circ} \mathrm{C}$. The standard deviation in one case was four percent, and in the other it was one percent. An uncertainty of not less than about five percent in $C_{g}$ must be recognized where computer fitting is needed because the intrinsic and inhomogeneity relaxations overlap. The uncertainty in $n$ appears to be about \pm 0.05 , based on the two independent estimates obtained as described above when the equivalent circuit is fitted to the data.

The equivalent circuit and other parameters for several specimens at temperatures near $230-250{ }^{\circ} \mathrm{C}$ are displayed in Table 5.

Table 5 Equivalent Circuit Parameters for $\mathrm{Y}$-doped $\mathrm{CeO}_{2}$ Ceramic Specimens at $230-250{ }^{\circ} \mathrm{C}$

\begin{tabular}{|c|c|c|c|c|c|c|c|}
\hline Specimen & $\begin{array}{c}\text { Cation } \\
\% Y\end{array}$ & $\begin{array}{l}\text { Flotation } \\
\text { Density } \\
\text { \%Theory }\end{array}$ & $\rho_{L}, \Omega \cdot \mathrm{cm}$ & $\varepsilon_{\mathrm{L}}$ & $R_{i} / R_{L}$ & $C_{i}, p F$ & $\begin{array}{l}n \\
-\end{array}$ \\
\hline & & & "Mixed 0 & xide' & & & \\
\hline B3 & 10 & 83 & $1.5 \times 10^{5}$ & 26 & 6.67 & 15 & .5 \\
\hline A 10 & 20 & 90 & $4.0 \times 10^{5}$ & 32 & 3.50 & 16 & .4 \\
\hline A12 & 20 & 94 & $1.0 \times 10^{6}$ & 16 & 2.33 & 17 & .5 \\
\hline HP8 & 10 & 94 & $3.1 \times 10^{5}$ & 33 & 1.43 & 225 & .4 \\
\hline & & & Chemically & Prepa & red" & & \\
\hline B7 & 8.5 & 84 & $2.6 \times 10^{4}$ & 45 & 14.6 & $1.7 \times 10^{4}$ & .9 \\
\hline B76 & 8.5 & 94 & $2.4 \times 10^{4}$ & 45 & 109 & $1.3 \times 10^{4}$ & .9 \\
\hline CHP-2 & 8.5 & $>99.5$ & $1.5 \times 10^{5}$ & 35 & 67.4 & $3.4 \times 10^{3}$ & .9 \\
\hline
\end{tabular}

Legend: $\rho_{L}=$ Resistivity calculated from $R_{L}$ and the dimensions $\varepsilon_{L}=$ Dielectric Constant calculated from $C_{g}$ and the dimensions 
The variation of the parameters from one group of specimens to the other appears to be outside limits of the error in their determination and to reflect real differences in the groups. A clue is seen in the data for specimen A12, which was found to have an obvious internal crack that provides an explanation for the rather low apparent dielectric constant and might also give rise to an abnormally large apparent resistivity. Such effects may account for some of the variation. The ratio $R_{i} / R_{L}$, on the other hand, might be expected to be less sensitive to internal cracks than the individual resistance values themselves, so that its variation is probably real. This is probably also true of the generally lower values of $\mathrm{P}_{L}$ and especially of the much higher values of $C_{i}$ and $n$ observed for the "chemically prepared" as compared to the "mixed oxide" specimens.

As indicated in Fig. 6a and Table 5, "chemically prepared" specimens mostly exhibited a considerable difference in time constant for the impedance relaxation due to the intrinsic properties from that attributable to inhomogeneity effects. We have therefore used several of these specimens to study the temperature dependence of both the intrinsic and inhomegeneity conductivities and also the total as measured by the 4probe method. An Arrhenius plot for this latter dc conductivity is shown in Fig. 7. There is a distinct bend in the plot at about $900{ }^{\circ} \mathrm{C}$, and two activation energies can be defined, as already observed by Kudo and Obayashi [5] and in a somewhat less definite fashion by Dirstine et a1. [70]. Tuller and Nowick [4], on the other hand, report 4-probe dc conductivity data on 10 cation percent $\mathrm{Y}$-doped $\mathrm{CeO}_{2}$ "mixed oxide" specimens that exhibit the characteristics of intrinsic conductivity, without an appreciable inhomogeneity contribution to the impedance, al though data reported in a later paper, Nowick et al. [71], for a two cation 


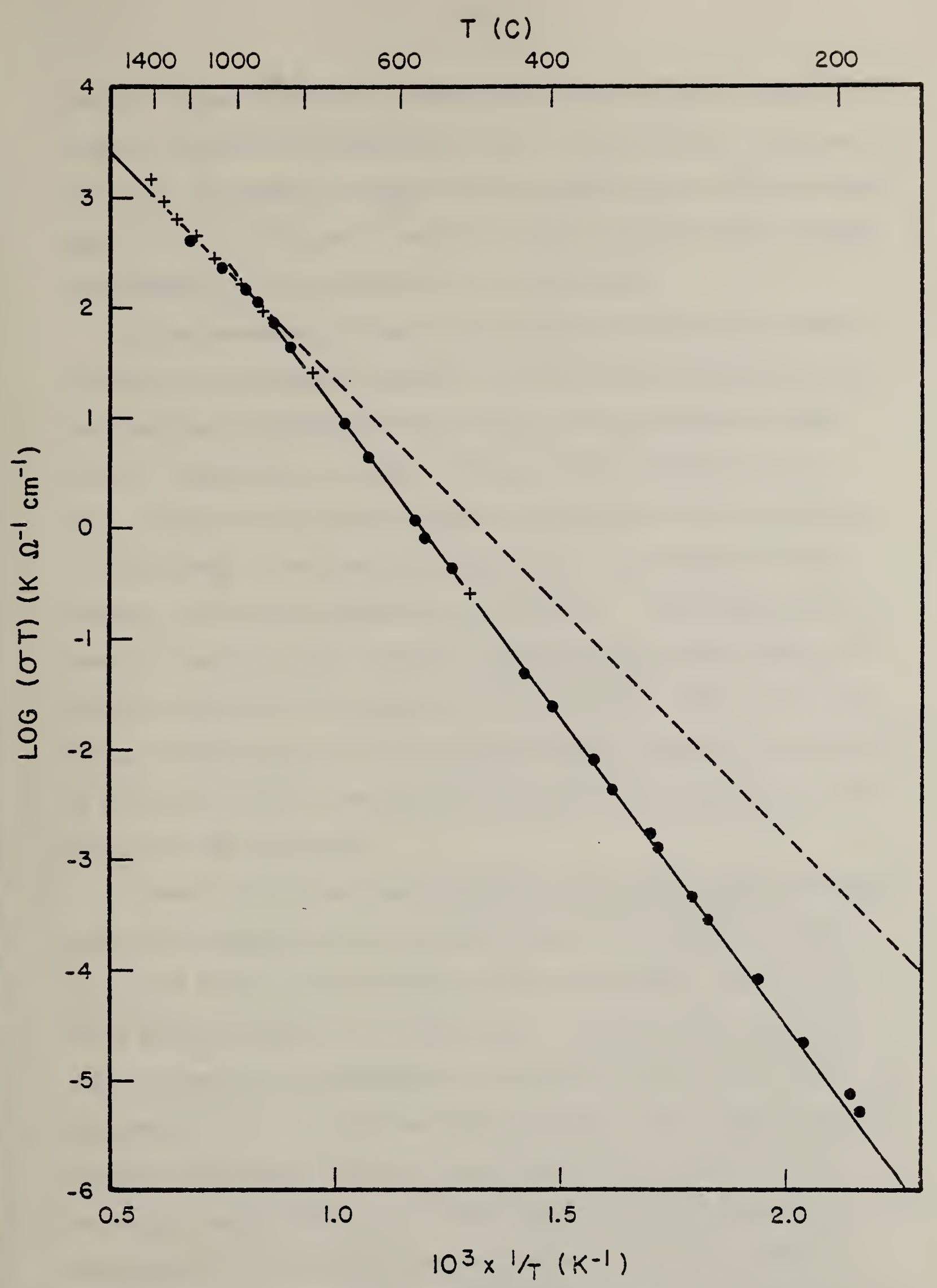

7: Temperature dependence of the conductivity of "chemically-prepared" Y-doped $\mathrm{CeO}_{2}$ ( 8.5 cation percent) ceramic, measured by the 4-probe dc method. 

percent $Y$-doped "chemically prepared" specimen do appear to exhibit a large and important inhomogeneity effect. The conductivity displayed in Fig. 7 was independent of oxygen partial pressures from $0.02 \mathrm{MPa}$ down to about $10 \mathrm{~Pa}\left(0.2 \mathrm{~atm}\right.$ down to about $\left.10^{-4} \mathrm{~atm}\right)$, over the range of measurement temperatures from below $200{ }^{\circ} \mathrm{C}$ to above $1000{ }^{\circ} \mathrm{C}$.

As the temperature increases the critical frequencies of various processes in the specimen increase, and the frequency range sampled by the electrical measurements moves to lower values relative to these critical frequencies. As shown by Bauerle [51] and Schouler et al. [52], the result in the complex plane representation for the impedance (or admittance) is the successive appearance or development of lowerfrequency arcs as the temperature is increased. In our studies here we observe three such arcs, intrinsic and inhomogeneity arcs already described and expected on the basis of the equivalent circuit, and at the highest temperatures at least the high-frequency side of an arc ascribed to electrode processes because of its sensitivity to the oxygen partial pressure in the atmosphere.

Figure 8 illustrates the appearance of such data at higher temperatures. The experimental data points (squares) are compared to those calculated for the same frequencies from the equivalent circuit determined by an 8-parameter fit to the data. For this purpose, the electrode impedance was represented by a second Cole-Cole distribution. The frequencies lie too low for the data to exhibit much influence from the intrinsic relaxation. The main arc derives from the inhomogeneity relaxation, and in this case exhibits a broad distribution of time constants $(n=0.7)$ although the specimen was "chemically prepared". The equivalent capacitance, $6.4 \times 10^{3} \mathrm{pF}$, is consistent with the "chemically prepared" material. Notable in this figure is the way in which the presence of the electrolyte relaxation effects the data in the 


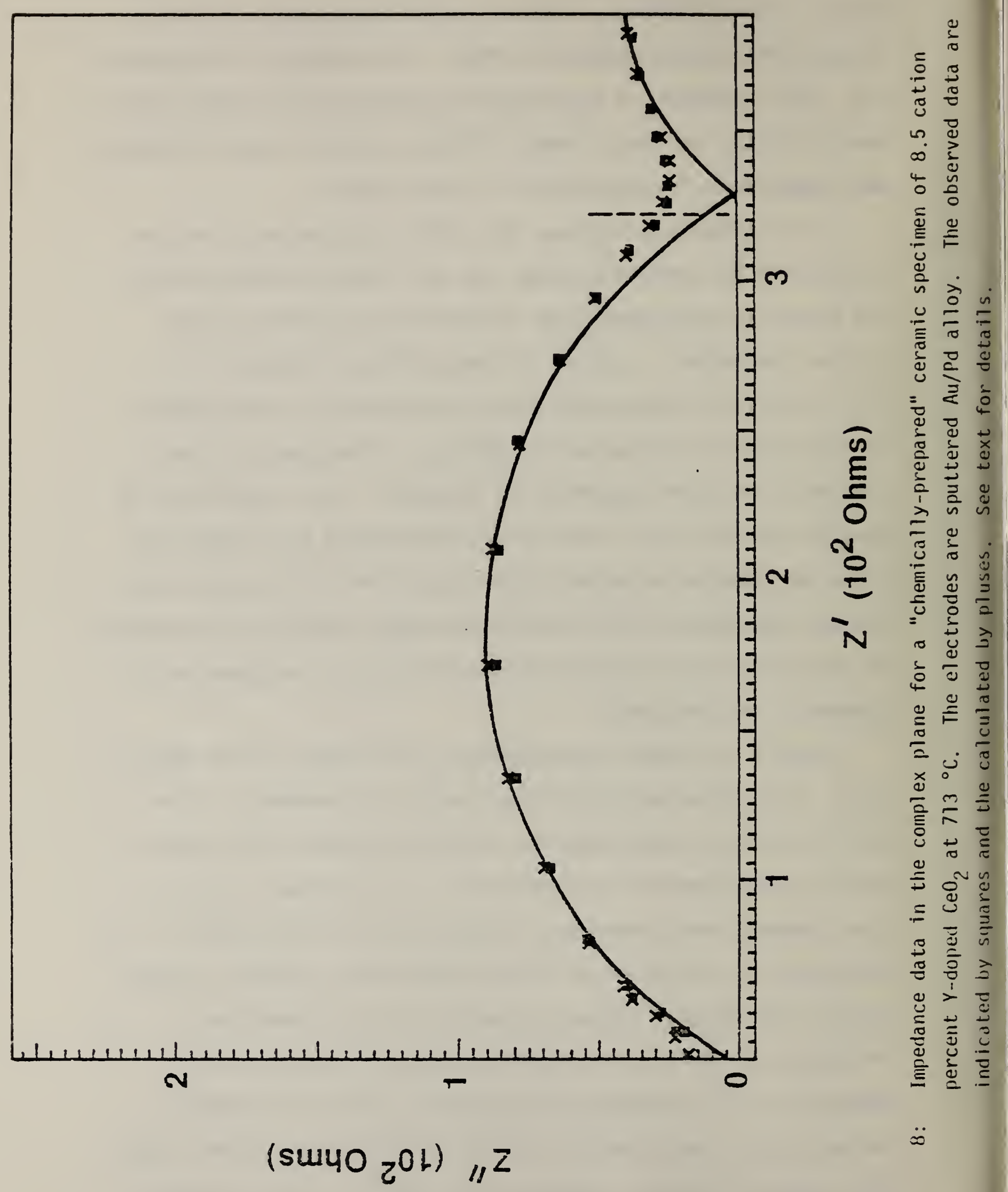


region of the inhomogeneity relaxation. Were the data to the right of the dotted line missing, a simple compass fit of an arc to the data might easily overestimate the inhomogeneity resistance by five percent and also the depression of the arc. This effect of the overlap of the relaxations becomes worse the broader the distribution of time constants and the closer the relaxations are in most probable time constant.

In Table 6 , we compare the total ac conductivity at $500{ }^{\circ} \mathrm{C}$, derived from $R_{L}+R_{i}$ and the specimen geometry, with the 4-probe dc conductivity at the same temperature, for "chemically prepared" specimens of 8.5 cation percent $\mathrm{Y}$-doped $\mathrm{CeO}_{2}$.

Table 6 Comparison of Total ac with 4-probe dc conductivities at $500{ }^{\circ} \mathrm{C}$ for "Chemically-Prepared" 8.5 cation percent $Y$-doped $\mathrm{CeO}_{2}$ Ceramic.

$\begin{array}{lll}\text { Method } & \text { Electrode } & \frac{\sigma, \mathrm{S} / \mathrm{cm}}{\text { ac }} \\ \text { ac } & \text { Au, sputtered } & 0.44 \times 10^{-4} \\ \text { ac } & \text { Au, sputtered } & 2.52 \times 10^{-4} \\ \text { dc } & \text { Pt, sputtered } & 1.16 \times 10^{-4}\end{array}$

Once again, there is variation from specimen to specimen beyond expected experimental error, but within this variation the ac and dc values are compatible, and no effect of the nature of the electrode is seen.

In Fig. 9 the temperature dependence of the 4-probe dc conductivity is compared to the independent ac measurements, for both total and intrinsic conductivity, for each of the three ac measurements listed in Table 6 above. The ac data have all been scaled to bring the total 


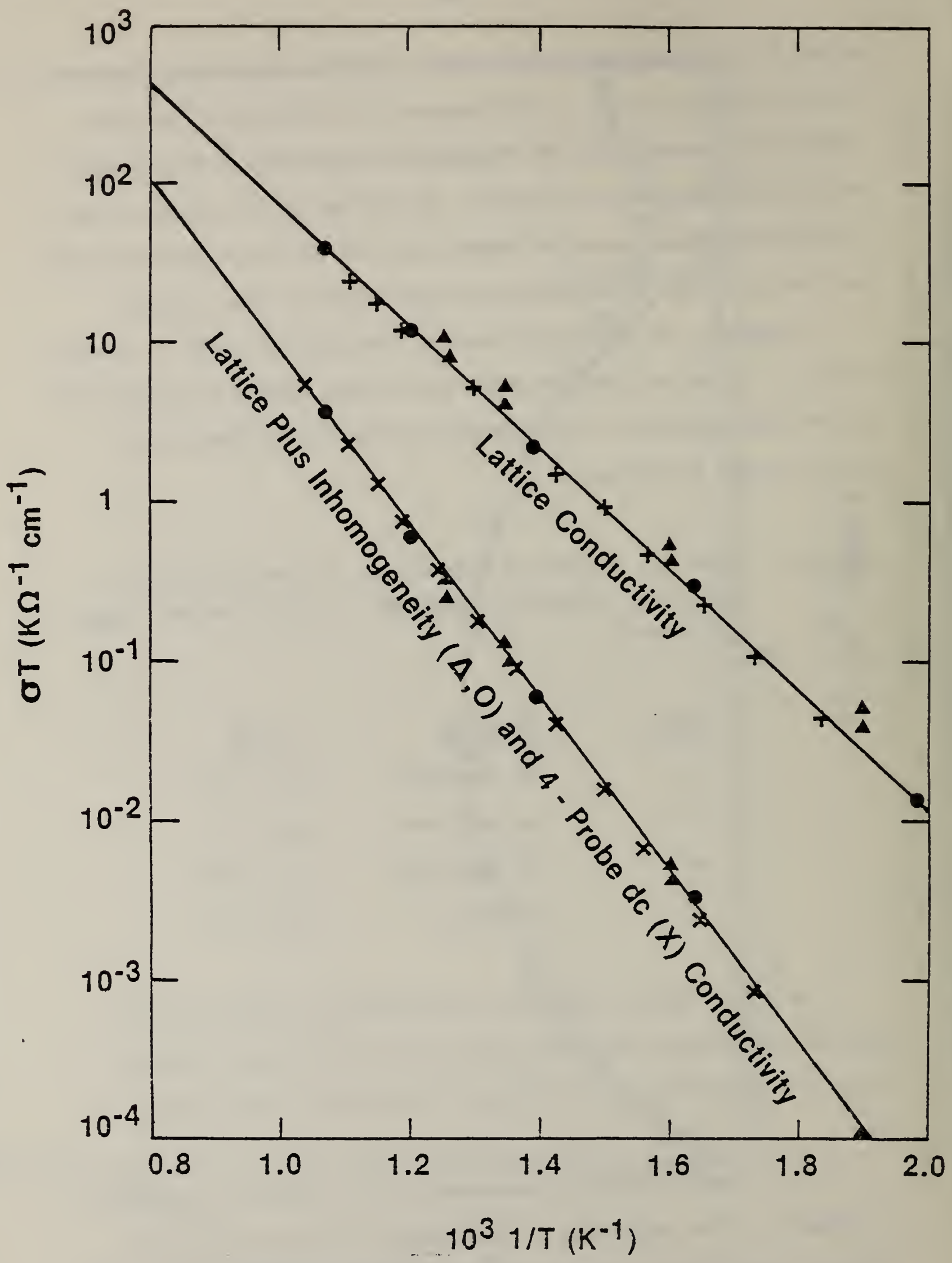

9: Comparison of temperature dependence of 4-probe and ac conductivities of "chemically-prepared" $Y$-doped $\mathrm{C} \equiv \mathrm{O}_{2}$ ( 8.5 cation percent) ceramic. The symbols,,$+ \Delta$, and refer to different ac specimens; $x$ indicates the 4 -probe de data on a fourth spesimen. 
conductivity into agreement with the 4 -probe dc value at $250^{\circ} \mathrm{C}$. Thus scaled, the data for both conductivities for the three specimens agree well among themselves and the total ac conductivity agrees with the 4 probe dc conductivity. Combining the ac measurements for the three specimens, we obtain the activation energies in Table 7.

Table 7 Activation Energies for ac and dc Conductivities in "Chemically-Prepared" 8.5 Cation Percent Y-doped $\mathrm{CeO}_{2}$ Ceramic

\begin{tabular}{|c|c|c|}
\hline Method & $E_{p}$, ev & $E_{2}$, ev \\
\hline $\mathrm{ac}$ & 1.08 & .76 \\
\hline dc & 1.10 & .82 \\
\hline
\end{tabular}

where $E_{1}$, represents the total ac or low-temperature dc conductivity, and $E_{2}$ the intrinsic ac or high temperature dc conductivity.

\section{Discussion}

The variation of the ratio $R_{j} / R_{L}$ with closed porosity, as measured by flotation density, for "mixed oxide" specimens shown in Table 5 suggests that for these materials at least the inhomogeneity impedance is related to the presence of internal pores in the material. Figure 10 shows that $R_{j} / R_{L}$ is roughly linearly dependent upon the volume fraction porosity, taken as one minus the density expressed as a fraction of the theoretical density, with a slope of about 37. It does not appear possible, however, to reconcile this behavior with the simple model for a dilute suspension of pores in a conducting matrix represented by Eqn. (10), and the correlation of Fig. 10 disappears if bulk density is used, thereby including open porosity as well. For spherical pores $\left(\varepsilon_{2}=1, x_{2}=0\right)$ in a conducting matrix the approximately linear behavior is suggested by Eqn. (10), but the slope should not exceed 0.5 , 


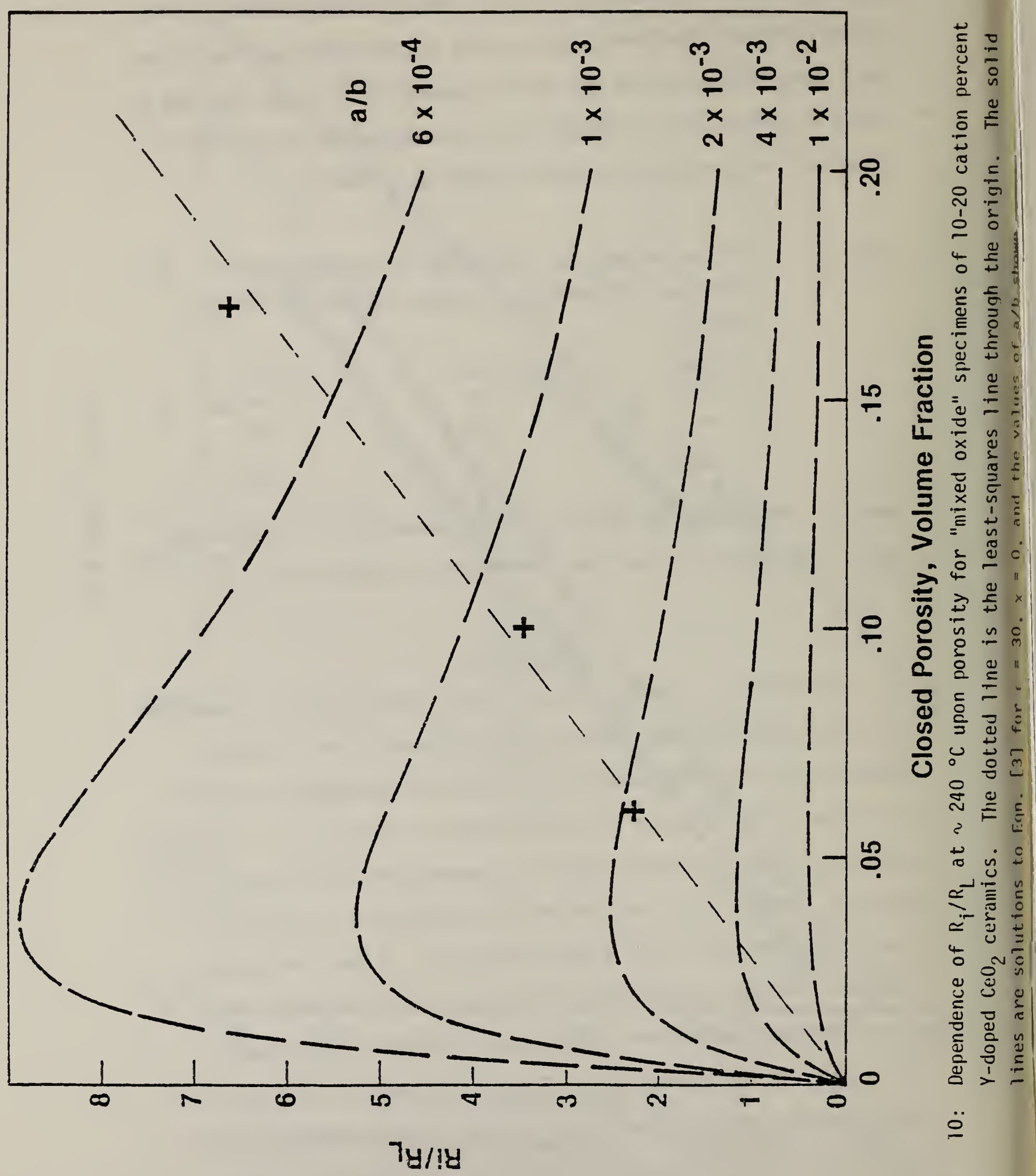


and should be less for a matrix dielectric constant greater than unity. On the other hand, oblate pores produce a larger inhomogeneity resistance than do spherical pores, but the behavior with respect to porosity is not simply linear. Figure 10 includes curves calculated using Eqn. (10) with a matrix dielectric constant of 30 and for the axial ratios shown. Furthermore, such a model would require that the temperature dependence of the inhomogeneity resistance be essentially the same as that of the intrinsic resistance, and this is not the case experimentally. It therefore does not appear possible to account for the observed data on the grounds of effects from isolated pores.

If, instead of pores, the distributed phase were to consist of second-phase particles, then the dielectric constant ratio in Eqn (10) would be smaller than for pores, resulting in larger values for $R_{j} / R_{L}$. In the event that the dielectric constants of the distributed phase and matrix were the same, Eqn. (10) would become, for non-conducting particles,

$$
\frac{R_{i}}{R_{L}}=\frac{A_{a}}{\left(1-A_{a}\right)} \text {. }
$$

For oblate spheroids, $A_{a}$ approaches unity as the axial ratio approaches zero, and thus rather large inhomogeneity resistances can occur when there are flattened regions present with conductivity lower than that of the matrix, such as might occur at grain boundaries. Why the extent of such regions should correlate with the closed porosity in these materials is not clear, however. Microscopic examination has not revealed any discrete grain boundary phâses, al though specimen HP8 is known from both $x$-ray diffraction and microscopic examination to be incompletely reacted and to contain discrete grains of fluorite and $\mathrm{Y}_{2} \mathrm{O}_{3}-\mathrm{C}$ structures. 

The equivalent circuit parameters for "mixed oxide" and "chemically prepared" specimens in Table 5 suggest several comparisons. The intrinsic lattice resistivity of the "chemically-prepared" material appears to be somewhat lower than that of the "mixed oxide" material, and may reflect the more homogeneous distribution of dopant in the former, as also suggested by the observation of somewhat sharper $x$-ray diffraction peaks for the "chemically-prepared" material. If the inhomogeneity impedance arises from variations in dopant concentration near the surface of the grains, it would also account for the broader distribution of time constants, reflected in the lower value of $n$ in Table 5 , for the "mixed oxide" materials.

The outstanding difference between the two materials, however, lies in the values for the equivalent capacitance, $c_{j}$, of the inhomogeneity impedance. This difference, amounting to several orders of magnitude, does not arise from differences in grain morphology. Grain shapes and sizes are essentially the same for the two cases, and the differences are reflected in the time constant $\tau$ [Eqn. (9)], which should be independent of morphology. For this same reason, the large value of $C_{i}$ for the "chemically-prepared" specimens probably does not simply indicate thinner regions of inhomogeneity. One mechanism from which large values of $C_{i}$ could result is partial compensation for the $Y$-doping at the grain surfaces either by incorporation of other impurities or by segregation of the dopant itself into the grain interior. As a result of this partial compensation, the concentration and therefore electronic conductivity of the surface region would be larger than that in the grain interior. For such an electronically conducting region in an otherwise electronically poorly conducting matrix, the dielectric constant would be enhanced by a factor $(1+\delta n / n)$ where $n$ is the electron concentration in the matrix and on the increase in the better conducting 
region. In our experiments the electronic conduction, and therefore electron concentration $n$, is very small, so that the dielectric enhancement in the surface regions could be large.

As shown by the data in Tables 6 and 7, the resistivity measured by the usual 4-probe method includes both the intrinsic and inhomogeneity contributions, and to obtain and interpret the intrinsic lattice conduction properties, the inhomogeneity contribution must be determined by ac measurements. As al ready recognized by Hooper [55] and Nowick, et al. [71], a break in the Arrhenius plot for conductivity, as seen in the data of Kudo and Obayashi [5], as well as in Fig. 7, can be due to this combination of inhomogeneity and intrinsic impedances and need not reflect changes in the intrinsic transport mechanisms themselves. The activation energies displayed in Table 7 are in reasonable agreement with the values already given by Kudo and Obayashi [5] and by Tuller and Nowick [4]. (intrinsic transport only) and Nowick, et al. [71], for about the same concentration of $\mathrm{Y}$ in $\mathrm{CeO}_{2}$ (10 cation percent). Kudo and Obayashi [5] derived their activation energies from plots of $\ln (0)$ vs. $T^{-1}$, rather than $\ln (\rho / T)$, and their activation energies must be increased by a few hundredths of an eV to be compatible with the others, based on $\ln (\sigma T)$ plots. The pre-expontential factor for the lattice conductivity from Fig. 5 is $5 \times 10^{5} \mathrm{SK} / \mathrm{cm}$, in reasonable agreement with Tuller and Nowick's [4] value of $2 \times 10^{5}$, and about an order of magnitude above a value appropriate to the data of Kudo and Obayashi [5].

\section{Summary}

Measurements of the impedance of $Y$-doped $\mathrm{CeO}_{2}$ ceramics containing about 10 or 20 cation percent $Y$ indicate that there is a sizeable contribution from inhomogeneities, perhaps grain boundaries, to the total impedance. Separating the intrinsic or lattice impedance from the 
inhomogeneity contribution appears to be possible using the frequency response of the impedance. The intrinsic conductivity is somewhat, but not heavily, dependent upon the specimen preparation. Values obtained here for the activation energy and pre-exponential factor for this intrinsic conductivity ( $\sigma T$ plot) are in reasonable agreement with values from the recent literature.

The inhomogeneity contribution to the impedance, and particularly the equivalent parallel capacitance, appears to be strongly dependent on the specimen preparation. For "mixed oxide" materials, the ratio of the inhomogeneity resistance to the intrinsic resistance scales approximately linearly with porosity, but the connection appears to be indirect. The existence of regions, perhaps at the grain boundaries, of variable dopant concentration is a possible explanation, with the incidence of such regions correlating with porosity. For the "chemically prepared" materials, a much larger equivalent inhomogeneity capacitance is observed than with "mixed oxide" materials. The differences cannot be accounted for on the basis of grain boundary geometry, but may reflect again a chemical effect at grain boundaries, such as an increase in the concentration of electronic charge carriers.

With polycrystalline specimens of materials of this kind the use of impedance spectroscopy, the analysis of the frequency dependence of the impedance over a wide frequency range, appears to be essential to a full understanding of the mass and charge transport processes.

\subsubsection{Slow Transients in Y-Doped $\mathrm{CeO}_{2}$}

In our last Annual Report [72] and in Quarterly Reports for 1 Apri1 to 30 June, 1979 and 1 July to 30 September, 1979, we discuss the observation of a slow transient in the voltage measured across the potential probes of a 4-probe dc conductivity measurement [73]. At temperatures 
of the order of $900{ }^{\circ} \mathrm{C}$ in air, the time constants of these transients were of the order of tens of seconds. The time constants obeyed the Arrhenius equation with an activation energy of $30.1 \mathrm{~kJ} / \mathrm{mol}(0.83 \mathrm{eV})$, while the slope of the overvoltage vs (time) ${ }^{1 / 2}$ plot seemed to depend on $\mathrm{P}_{2}{ }^{1 / 2}$, where $\mathrm{P}_{\mathrm{O}_{2}}$ is the oxygen partial pressure.

This phenomenon suggests one of two explanations. The overvoltage reflects a change in relative oxygen activity at the potential probes induced by the initation of a current; and, therefore, an oxygen flux, through the specimen.. The oxygen activity at the cathode can be expected to fall, and to rise at the anode, when this flux is turned on. Apparently these changes in oxygen activity are transmitted to the potential probes by diffusion of neutral oxygen out of the specimen, which appears possible either as oxygen atoms or molecules moving presumably in the grain boundaries, or else as coupled electrons and oxygen vacancies in ambipolar diffusion in the lattice.

We are investigating these models by numerical solution of the diffusion equation with appropriate boundary conditions. The diffusion problem for volume diffusion of a neutral oxygen atom has been cast in finite-difference form and solved for a variety of values of oxygen partial pressure in the atmosphere and of the ratio of diffusion coefficient for neutral oxygen in the electrolyte to that in the electrode, for comparison to the experimental observations.

The results of this partial study shows that the neutral oxygen diffusion model reproduces rather well the experimental data. However, the study is not complete until a similar investigation of the ambipolar diffusion model has been compiled, so that a comparison between the two models can be made and one presumably eliminated. It is planned during the next year to complete this study. 


\subsubsection{Precipitation Phenomena in Mg-Doped $\mathrm{ZrO}_{2}$}

Zirconia electrolytes possess the high-conductivity fluorite structure by virtue of the presence of aliovalent dopant cations. Without these stabilizing cations, the fluorite structure transforms to tetragonal at temperatures below about $2400{ }^{\circ} \mathrm{C}$ or to monoclinic below about $1240{ }^{\circ} \mathrm{C}$, and loses the very high oxygen-ion conductivity. If in fue 1 cell operation a long-term drift of the dopant cations occurs under the force applied by the potential drop across the fuel cell solid electrolyte, and a loss of the fluorite structure results, the overall effect could be a degradation of the fuel cell output and efficiency.

The de-stabilization of the fluorite structure through loss of dopant cation is expected to occur by precipitation of the tetragonal phase in the form of very small particles [74]. These particles would fulfill the condition, discussed in Section 2.1.2, that their dielectric constant is not very different from that of the matrix; and, therefore, they could produce an appreciable inhomogeneity impedance. Figure 11 shows a comparison of the impedances in specimens quenched from the solid solution and two-phase regions [75]. The precipitation anneal results in the development of an additional arc in the impedance plot. The additional arc is quite depressed, the value of $n$ in the cole-cole equation (Eqn. [2.1.2-1]) being 0.69. This suggests a rather broad distribution of particle properties, which is to be expected on the basis of the precipitation mechanism as described by Heuer [74], in which the composition follows the solvus lines as the specimen temperature is changed during reaching and leaving of the precipitation anneal temperature.

The ratio of the inhomogeneity resistance attributable to the precipitates to that from the rest of the specimen is about 0.2 . 


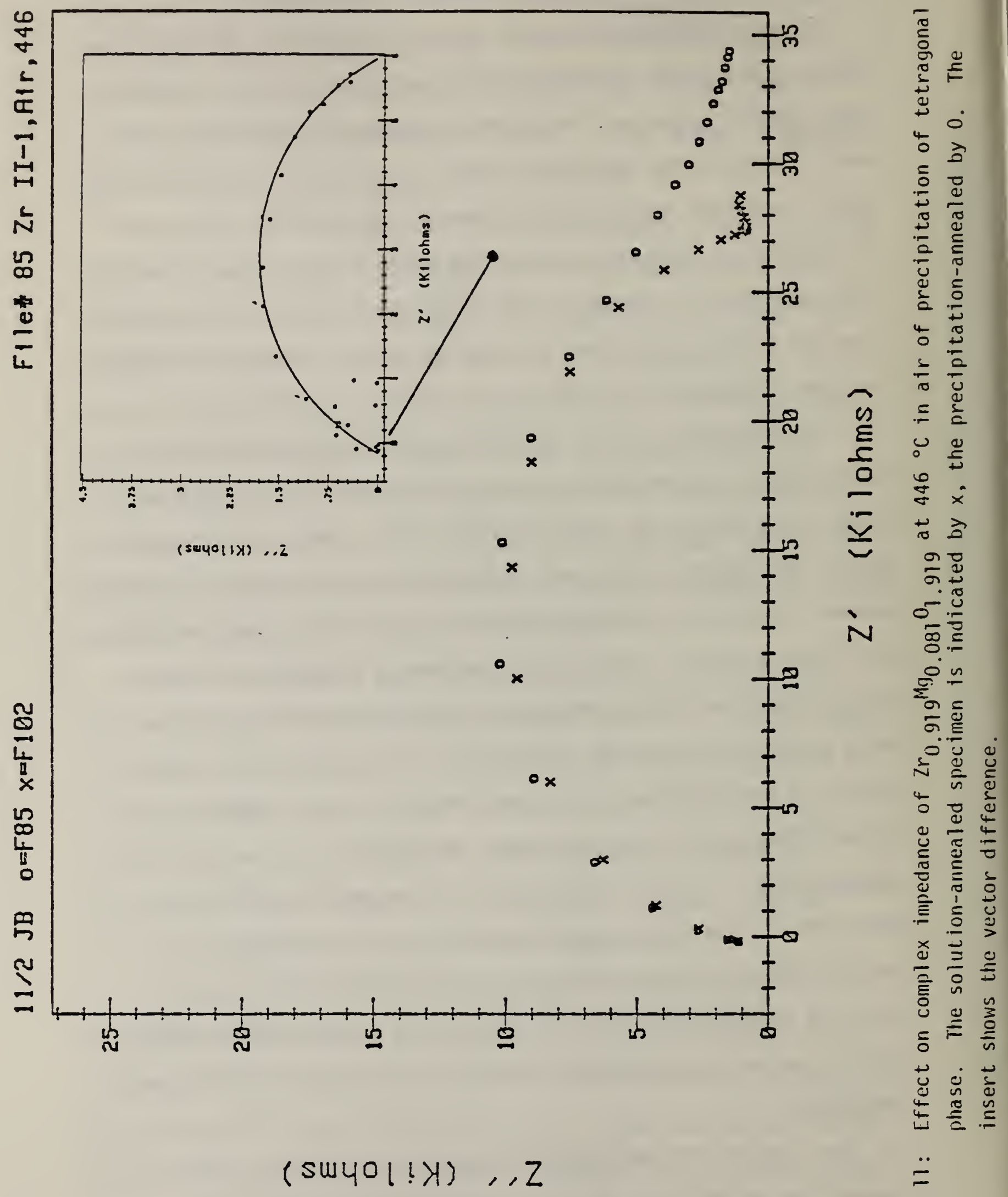


According to Eqn. (16) this ratio for spherical non-conducting particles of the dielectric constant as the matrix would be

$$
\mathrm{Ri} / \mathrm{Rs}=\mathrm{P} / 2,
$$

where $\mathrm{Ri}$ is the inhomogeneity resistance introduced by the precipitates, Rs is that from the rest of the specimen, and $P$ is the volume fraction of precipitate. Thus, for spheres, the data suggest $P \sim 0.4$. The phase diagram given by Grain [76] and sketched in Fig. 12 suggests that this value might just be reached if precipitation were to take place at the eutectoid temperature of about $1400{ }^{\circ} \mathrm{C}$, but that a smaller value is to be expected. Somewhat oblate ellipsoidal, instead of spherical particles, could account better for the data.

\subsection{Interconnector Materials}

2.2.1 Oxygen Sensitive Electrode Impedance in $\mathrm{Sr}$-Doped $\mathrm{LaCrO}_{3}$

\section{Introduction}

In order to connect cells together in a high-temperature fuel cell, the interconnector material must be a good electronic conductor at operating temperatures $\left(\sim 1000{ }^{\circ} \mathrm{C}\right)$ and in a wide range of oxygen partial pressures (from air to the fuel mixture), must not allow passage of too many oxygen ions or atoms, and must be compatible with the other materials present. These conditions limit the choice of material drastically.

One of the candidate materials for this application is Sr-doped $\mathrm{LaCrO}_{3}$, al though there is some evidence for oxygen transport [77]. It was not clear whether this 0 transport was intrinsic to the crystal lattice or occurred mainly in the grain boundaries. It, therefore, appeared profitable to study this material using the impedance spectroscopy technique. This work was done in collaboration with 


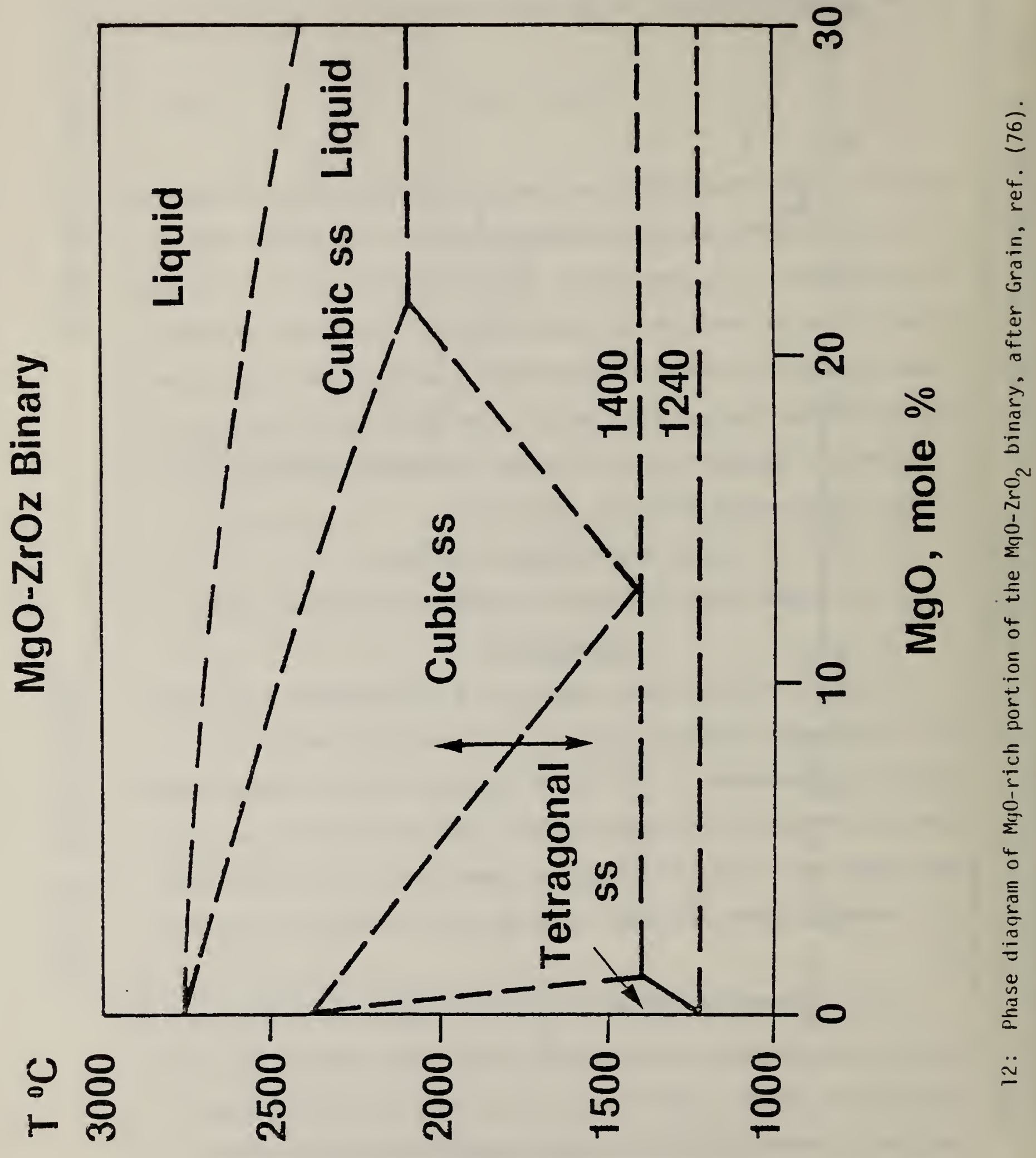


Richard A. Snellgrove of the General Refractories Co., who supplied the specimens and their characterization.

\section{Results}

The major result of the work to date is the observation of an oxygen-sensitive electrode impedance with noble-metal electrodes on $\mathrm{Sr}$ doped $\mathrm{LaCrO}_{3}$. Changes induced by changing the oxygen partial pressure in the atmosphere occurred at temperatures as low as room temperature and in times of the order of days or weeks. We discuss here experiments demonstrating this sensitivity and bearing on the nature of this electrode impedance.

The ceramic samples used in this study were prepared by firing mixtures of oxides at $1750{ }^{\circ} \mathrm{C}$ in air. The samples had the composition $\mathrm{La}_{0.992} \mathrm{Sr}_{0.008} \mathrm{CrO}_{3}$ and were black in color. The density was 97 percent of the theoretical value. The grain size was approximately 3-10 $\mu \mathrm{m}$. Sharp $x$-ray patterns were obtained, and the material appeared to be single-phase. Impedance measurements, made with an RMS amplitude of $0.3 \mathrm{~V}$ at frequencies from $56 \mathrm{~Hz}$ to $13 \mathrm{MHz}$, and two-probe and four-probe dc measurements were used to examine the electrical properties from $52{ }^{\circ} \mathrm{C}$ to below $-100{ }^{\circ} \mathrm{C}$ under atmospheres of air, tank nitrogen and tank oxygen. For the impedance and the two probe $\mathrm{dc}$ measurements, square plate samples with dimensions $0.8 \times 0.8 \times 0.2 \mathrm{~cm}$ were used. Sputtered platinum and evaporated gold electrodes were applied to surfaces polished to $0.5 \mu \mathrm{m}$ diamond abrasive powders and then cleaned. These electrodes were either symmetrical, with a diameter of $.64 \mathrm{~cm}$, or were unsymmetrical with diameters of 0.15 and $0.64 \mu \mathrm{m}$, for a ratio or areas of 0.057 . Point contacts opposite large area electrodes were made by pressing the tip of a wire on the unelectroded surface. Bar samples with dimensions of $1 \times 0.12 \times 0.12 \mathrm{~cm}$ were used for four-probe dc measurements, using silver paste contacts. 
Figure 13 shows the impedance in the complex plane for the sample, at two temperatures in tank $\mathrm{N}_{2}$, with frequency as a parameter. The arrow at the left on the real axis indicates the bulk resistance as measured with the four-probe specimen, and demonstrates that the arc to the right, at lower frequencies, represents an electrode effect.

Figure 14 demonstrates the sensitivity of this electrode impedance to the oxygen activity of the atmosphere. For the data of Fig. 14, the sample was first held in at atmosphere of tank $\mathrm{O}_{2}$ at $52{ }^{\circ} \mathrm{C}$ until all changes ceased; and then the atmosphere was rapidly changed to tank $\mathrm{N}_{2}$ and the sample held at constant temperature in this atmosphere. The impedance was occasionally measured as a function of frequency, and the equivalent parallel resistance and capacitance determined by fitting the data to a Cole-Cole [53] function. There was some quantitative variation among specimens depending on prior heat treatment, but the main effects were independent of specimen. Over a period of several weeks, the electrode resistance increased by a factor as large as 35 . The capacitance decreased at the same time, but by less than a factor of two.

After replacement of the $\mathrm{N}_{2}$ by $\mathrm{O}_{2}$, still at $52{ }^{\circ} \mathrm{C}$, the resistance decreased again, much more rapidly than the increase that had occurred in $\mathrm{N}_{2}$, and the capacitance increased. This reduction and reoxidation process is essentially reversible, the resistance and capacitance after the second oxidation returning to close to their original values. The process is strongly temperature dependent, and occurs slowly enough below room temperature so that measurements up and down the temperature scale can be made without hysteresis. At low temperatures, the impedance data allow a determination to be made of the bulk resistance that agrees in detail with the four-probe dc measurements, and gives values independent of the changes in oxidation state carried out at $52{ }^{\circ} \mathrm{C}$. The 


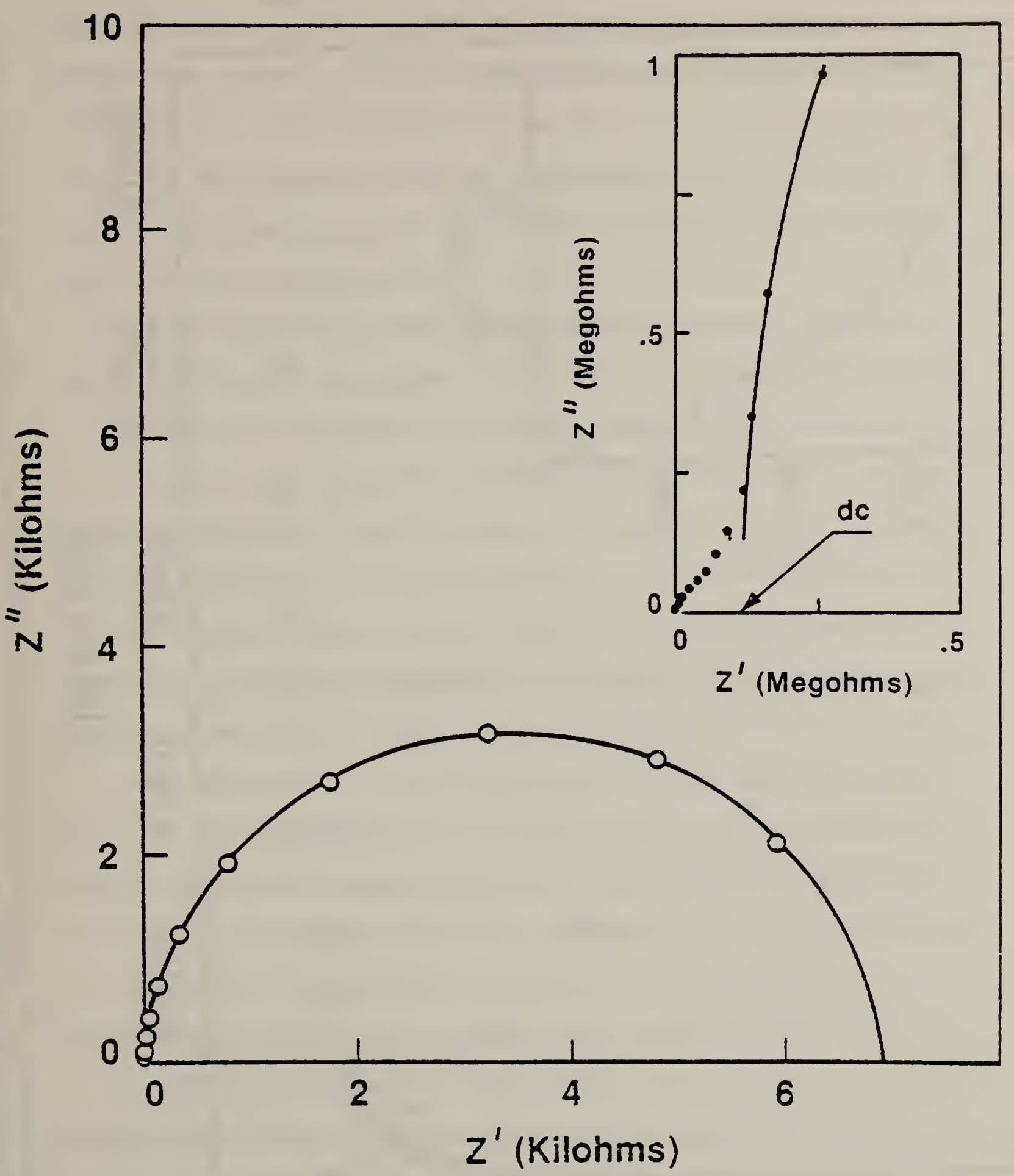

13: Typical impedance spectrum ( $5 \mathrm{~Hz}$ to $13 \mathrm{iHz}$ ) of $\mathrm{La}_{0.992} \mathrm{Sr}_{0.008} \mathrm{CrO}_{3}$ at room temperature, equilibrated with tank $\mathrm{N}_{2}$ at $52{ }^{\circ} \mathrm{C}$. The high frequency region contains a temperature-dependent fine structure. Inset shows this fine structure revealed by making measurements at $-130^{\circ} \mathrm{C}$. 


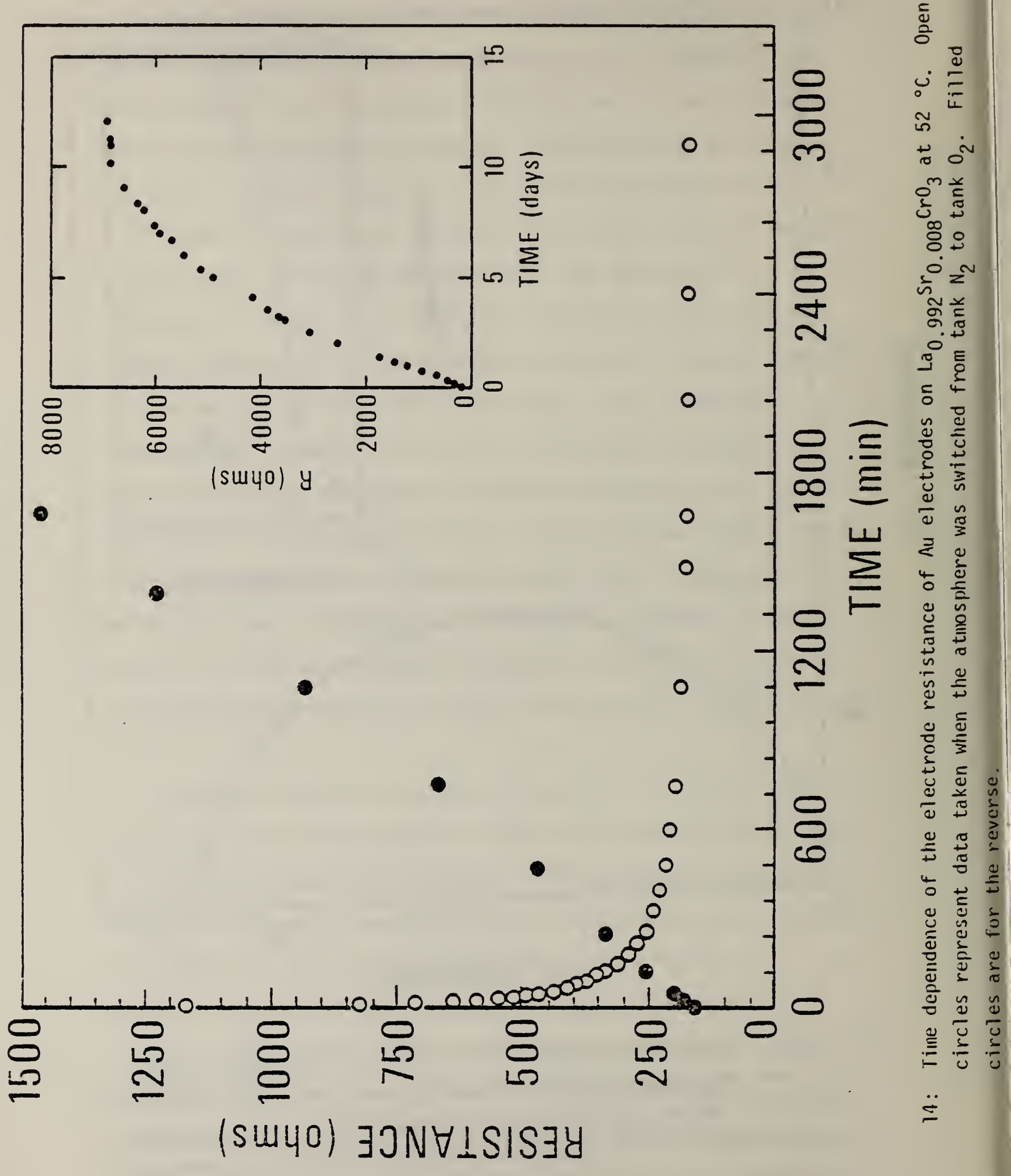


bulk resistance and the electrode resistance yielded approximate linear graphs when plotted in the form of $\log (R / T)$ vs. $T^{-1}$ in the range from -160 to $75{ }^{\circ} \mathrm{C}$. The activation energies were $0.16 \mathrm{eV}$ for the bulk process; for the electrode process the values were $0.21 \mathrm{eV}$ when equilibrated with dried tank $\mathrm{O}_{2}$ at $52{ }^{\circ} \mathrm{C}$, and $0.33 \mathrm{eV}$ when exposed for three weeks to dried tank $\mathrm{N}_{2}$ at $52{ }^{\circ} \mathrm{C}$.

The existence of a contact resistance and capacitance suggests a barrier layer at the electrodes. Experiments at room temperature in air on the effect of bias on both the current and the differential capacitance indicate that the barrier does not behave like a simple Schottky depletion layer [78]. The I-V curves are roughly symmetrical about zero bias and exhibit very little rectification. The capacitance is not strongly changed by bias, but the effects are also quite symmetrical, the capacitance at first decreasing with increasing bias; and then, when the bias exceeds about 20 volts, decreasing again.

When plotted on a $\log -\log$ basis, the I-V curves exhibit an ohmic region at low bias followed by one square-law region and a transition to another when the bias exceeds about ten volts. Applying a steady bias for several hours always resulted in a decrease in the ohmic resistance. For instance $20 \mathrm{~V}$ for two hours decreased the ohmic resistance by two orders of magnitude. This effect also was symmetrical and reversible.

A sensitivity of the electrical properties to oxidation or reduction is to be expected in this material, which appears to be a p-type conductor with the $\mathrm{Sr}^{2+}$ ions acting as acceptors [79]. In low-oxygen atmospheres, some reduction will take place, producing oxygen vacancies which, because they act as donors, will at least partially compensate the $\mathrm{Sr}^{2+}$ ions. Hence, the number of uncompensated acceptors will change with the oxidation state. That changes in oxidation state are reflected in electrode properties at temperatures as low as room temperature is 
consistent with the apparent thinness of the critical region under the electrodes. The impedance measurements at $-109{ }^{\circ} \mathrm{C}$ revealed enough of both bulk and electrode arcs simultaneously to allow estimates to be obtained for both the intrinsic and electrode capacitances. From the measured thickness of the specimen and assuming the same dielectric constant for bulk and surface regions, we estimate the barrier width to be about $1.6 \times 10^{-5} \mathrm{~cm}$. For the sake of comparison, if we consider a Schottky barrier with a barrier height of one $V$, this suggests an uncompensated acceptor concentration of about $4 \times 10^{16} \mathrm{~cm}^{-3}$ in this surface region, very much less than the overall $\mathrm{Sr}^{2+}$ concentration of $1.3 \times 10^{20} \mathrm{~cm}^{-3}$ but reasonable if, in the surface, reduction has occurred, introducing almost enough oxygen vacancies to compensate the $\mathrm{Sr}^{2+}$ ions, so that the chemical formula is close to $\mathrm{Sr}_{x} \mathrm{La}_{1-x} \mathrm{CrO}_{3-\mathrm{x} / 2}$, where $x=.008$ in our specimens. Why the surface should behave so differently from the interior is not clear.

\section{Summary}

Barrier layers are formed on $\mathrm{Sr}$-doped $\mathrm{LaCrO}_{3}$ that give rise to an appreciable electrode impedance with electrodes of Au or Pt. The corresponding electrode resistance is quite sensitive to the oxygen activity in the atmosphere, following atmospheric changes at temperatures near room temperature with time constants of the order of minutes or days. The electrical properties of these barrier layers at room temperature do not conform to the models of simple Schottky layers on semiconductors, but exhibit changes in current and differential capacitance much more symmetrical in the applied bias.

\section{Acknowledgments}

The specimens and much information about them were furnished by R. A. Snellgrove, of the General Refractories Co., who is coauthor of a version of this report being submitted for publication. 


\subsection{Development of Instruments}

2.3.1 Low-Frequency and Pulse Operation of Microprocessor-Controlled Potentiostat

\section{Introduction}

In previous work $[72,80]$, we have described the development of a microprocessor control and fast data acquisition system for use with a standard laboratory potentiostat. As discussed in ref. [72], this system is, in principle, capable of ac and pulse measurements, and offers a low-frequency capability below the range of our present impedance-measuring equipment $(\sim 10 \mathrm{~Hz})$. Work this past year has been directed toward realizing this potentiality. As discussed previous1y [80], this has necessitated the design and construction of a new converter board. The construction of the new converter board has been plagued by component delivery problems. The unavailability of normallycommon components led to a total review of the design with the intent of redesign around more available parts. The result of this reexamination has been a modification of the original design. These modifications, the most important of which is a change to the addressing scheme, will be discussed in detail below.

Much of the year was occupied with software. The difficulties encountered with interfacing the disk units (to be described later) led us to examine the possibility of writing our own operating system. We soon concluded that this would be even more difficult, and the idea was dropped.

\section{Hardware}

The fundamental design of the converters has remained the same. The majority of the changes made have been in the portions of the circuit devoted to the decoding of the addresses in the circuit. Several changes have been made to the disk driver circuit. (It is worth noting 
here that many of the changes to this part of the circuit are for the purposes of improving the efficiency of programing and are a direct result of the generation of the Disk Driver Routines.) The final alterations to be noted are in the DAC converter Reference Amplifiers.

The changes in the Reference Amplifiers will be discussed first. The originally specified REF-01 and REF-02 are among the devices not received. (See Figure 34 in Annual Report, Jan. 1978 to Dec. 1978, Ref. [80].) They have been replace by $M C 1404-10$ and $L M-10$, respectively. On the schematic, these changes are shown as label changes, but mechanical modifications due to physical device configurations are necessary. The electrical specifications of the REF-01 and REF-02 are apparentiy more desirable, and a return to the original design would be justified when the devices are received. (Note that there is an error in the references figure. The register select line labelled RC' should be relabelled as $\mathrm{R5}$.)

The rest of the changes to the system are summarized below. Reference should be made to the previously published schematics (specifically, Fig. 28 and Fig. 31 in the Jan. 1978 to Dec. 1978 Annual Report, Ref. [80].) The addressing changes will be discussed first.

The addressing requirements of the segments of the disk driverconverter section of the system are shown in Table 8 . (Note that the base address of this section (BFCO Hexadecimal) can be changed by appropriate inversions of the address line inputs to the 74513313 input NAND date. Also, that the addresses in the available rarige up to BFFF not used by the Disk Driver converter section can be decoded by the use 
of the BFDO hex and BFFO lines as Enables to decoders for the four lowest address Tines.) The primary chip Enables are generated by the combination of the $74 S 133$ NAND date and half of the 745133 two line to four line Dual decoder. The Enables (inverted where necessary) are used in combination with the four lowest address lines to generate each necessary unique address. Although it's not an address function, the other half of the 74LS139 generates the acknowledge strobe to the appropriate DMA channel, which is a decode operation and, therefore, included in this discussion.

Table 8

Driver-Converter Section Addressing Requirements, Disk

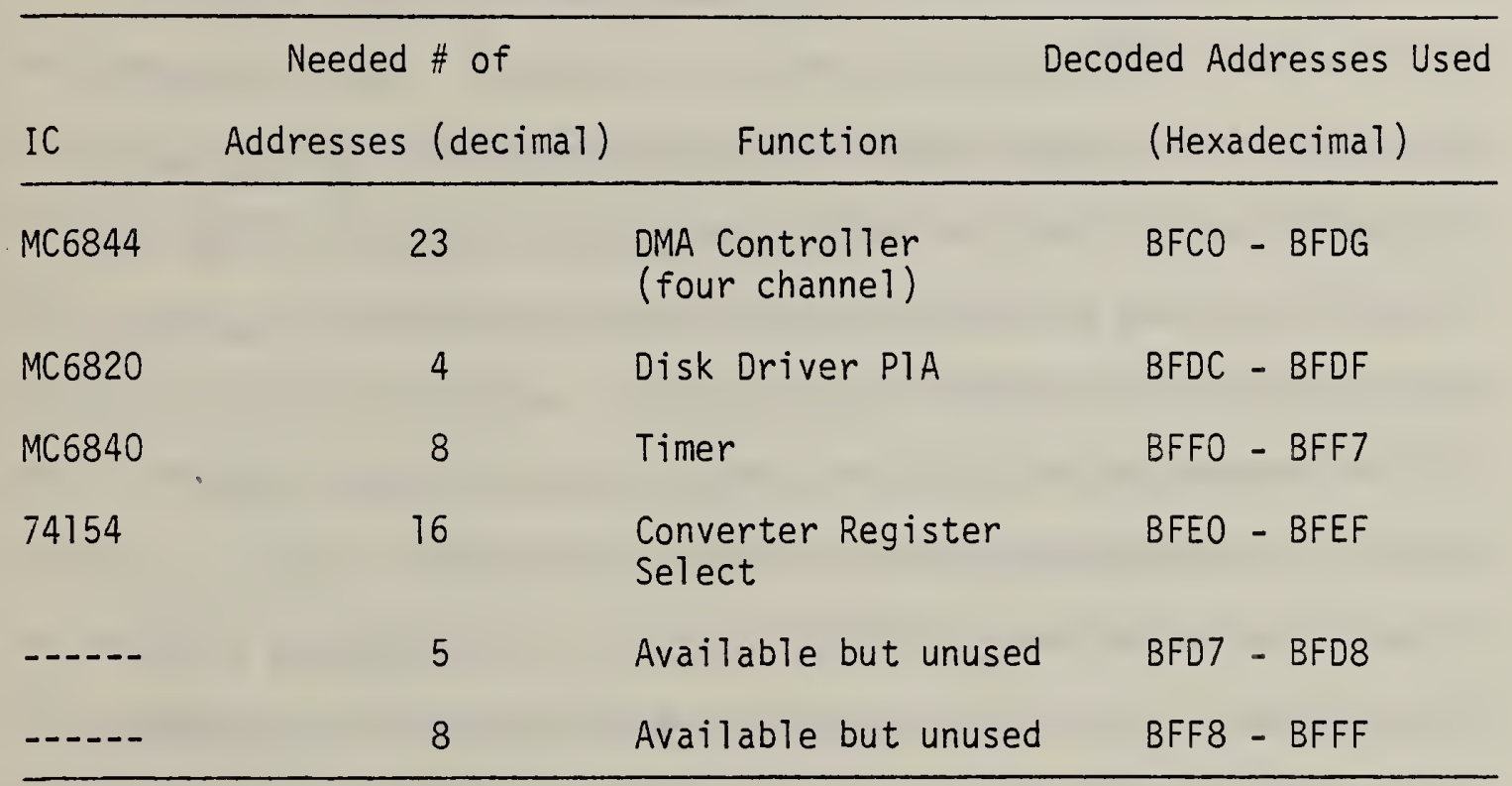

The resulting address decode system is simpler to understand, because of it's more straightforward layout, and results in somewhat fewer IC's needed.

The final revisions to be discussed are those made to the Disk control part of the PIA. As mentioned earlier, the primary reason for these changes was the improvement of programming efficiency. It should 
be noted in passing, that the original control concepts can still be implemented in the revised version. The alterations have simply added another mode which is more efficient.

The major changes made have been to the manner in which the $\overline{D T R}, \overline{D T A K}, \overline{B U S Y}$ and $\overline{E R R O R}$ signals are handled. In the original version, $\overline{D T R}$ going low caused the PIA CBI Interrupt flag to be set. If the Interrupt was masked, this condition would be detected by reading the PIA B control register. If the Interrupt was not masked, the system would automatically transfer to an Interrupt handling routine. In either use, the Interrupt flag would have to be cleared, data transferred, $\overline{D T A K}$ set low, and then high. These operations would be distinct sets of instructions for each function. By reassigning $\overline{D T R}$ to the PIACAI Interrupt, and CA2 to $\overline{D T A K}$, we can improve the situation. In this case, we can program the A side of the P1A for CA2 pulse mode. Now upon detection of $\overline{D T R}$ low, we transfer data and read the A data side of the PIA. This read operation automatically clears the Interrupt flag and sends a negative going pulse on $\overline{D T A K}$. Thus, we do in one instruction an operation that involved a minimum of five instructions in the original design. Those considerations that influenced the first version (e.g., control of the pulse length of DTAK) can still be accomodated in the present design, simple by changing the operational mode of the PIA. Similarly, the rearrangement of the $\overline{B U S Y}$ and $\overline{\text { ERROR }}$ signals so that either one activates the $C B 1$ Interrupt flag allows the same kind of data handling as above, upon completion of a data transfer or detection of an error. Note that $\overline{B U S Y}$ goes high when the transfer is completed, while $\overline{\text { ERROR }}$ goes low when one occurs. Thus, the Interrupt signal has to be the NAND of ERROR with $\overline{B U S Y}$ inverted. 


\section{Software: Interfacing to a Commercially Available Operating System}

An operating system for a microcomputer is a program that provides control of a11 the system functions. These functions include input, output, dynamic file management, floppy disk control, etc. Most of these functional programs are not hardware independent. Thus, the adaptation of an operating system written for one hardware configuration to another configuration is a difficult procedure. This is even more true when the source code for it is not available. However, the programming of an entire system is even more difficult and time consuming. Our decision to adapt a commercial system took note of these factors. A short discussion of the adaptation method follows.

The first step in this procedure is to write programs for the necessary disk driver functions. (Driver in this case is the control program to set up and start the disk for a particular command function, and to manage the transfer of data to (from) the disk from (to) memory.) When these are completed, they must be matched to the particular operating system (OS) selected. This is done by finding the format used to pass parameters and error signals back and forth between the OS and the drivers. If this information is not provided by the OS manual, the existing driver programs in the object code for the OS must be found, disassembled and translated into source code. When this is completed, our drivers are modified to reflect the now known parameter format. The next step is to try and find all program calls to the disk drivers and to other input--output routines. Wherever these are found, they must be replaced by calls to our disk drivers and I/O routines. The I/0 routines, of course, are essentially the ones already written for the hardware configuration. Finally, the Interrupt handling routines in the operating system must be translated into source code, and modified so that the occurrence of an Interrupt will not destroy the program. 
We have two operating systems potentially available for use. The relevant driver sections of both have been disassembled and are being translated into source code. The primary difficulty seems to rest in the format and handling of the error signals from the disk unit. At present, it appears that it will be necessary for us to write a routine that will simulate the appropriate error conditions upon receipt of a signal from the drive.

The second most important difficulty is that of Interrupt handling. We are not, as yet, able to pinpoint the areas in the OS where these routines are. (The programmers who wrote the OS have used self-modifying code in some regions of the program. This leads to some confusion.) We feel, however, that this problem is capable of resolution once appropriate drivers are available.

$I / O$ and disk driver calls are resident throughout the OS. Finding all of them is simply a matter of disassembling the full code.

The latest versions of our disk driver are completed and are written around the new hardware design. These drivers are written to mesh with one of the operating systems available to us. One program, in addition to the disk driver routines, is included that has not been discussed. This is the routine used to format new disks. Each os has its own data and directory format requirements for a disk. Thus, every new disk must be preformatted tefore it can be utilized by the operating system.

of the remaining drivers, one has to be operating system-independent. This routine is to reside in P.OM and functions as a loader for the operating system-independent drivers and the loader program resident in 
the OS. This OS independence is qualified by the proviso that the size of the sectors on disk must correspond to that required by the 0 . Thus, our BOOT program requests the identification of the OS to be loaded. 


\section{References}

1. W. Schottky, Wiss. Veroff. Siemenswerke, 14, H2, 1 (1935).

2. E. Baur and H. Preis, Z. Elektrochem., 43, 727 (1937).

3. K. Kiukkola and C. Wagner, J. Electrochem. Soc., 104, 379 (1957).

4. H. L. Tuller and A. S. Nowick, J. Electrochem. Soc., 122, 255 (1975).

5. T. Kudo and H. Obayashi, J. Electrochem. Soc., 122, 142 (1975); 123, 415 (1976).

6. J. W. Patterson, E. C. Bogren and R. A. Rapp, J. Electrochem. Soc., 114, 752 (1967).

7. A. S. Nowick and D. S. Park, "Fluorite-Type Oxygen Conductors", in, Superionic Conductors, G. D. Mahan and W. L. Roth, Eds., Plenum Press, New York, 1976.

8. J. Lefevre, Ann. Chim., $\underline{8}, 135$ (1963).

9. R. Collongues, F. Quelyroux, M. Perez y Jorba and J. C. Gilles, Bul1. Soc. Chim. Fr., 1141 (1965).

10. M. R. Thornber, D. J. M. Bevan and J. Graham, Acta. Crys., B24, 1183 (1968).

11. J. G. Allpress and H. J. Russe11, J. Solid State Chem., 15, 68 (1975).

12. R. E. Carter and W. L. Roth, "Conductivity and Structure in CalciaStabilized Zirconia", in, Electromotive Force Measurements in High-Temperature Systems, C. B. Alcock, Ed., Elsevier, New York, 1968.

13. D. Miche1, Matl. Rsch. But1., 8,943 (1973).

14. D. Michel, Rev. Int. Hautes Temp. Refract., $\underline{9}, 225$ (1972).

15. B. Hudson and P. T. Moseley, J. Solid State Chem., 19, 383 (1976).

16. W. H. Rhodes and R. E. Carter, J. Am. Chem. Soc., 49, 244 (1966). 
17. H. H. Willard and N. K. Tang, J. Am. Chem. Soc., 59, 1190 (1937).

18. L. Gordon, Ana 1. Chem., 27, 1704 (1955).

19. L. Gordon, Record Chem. Progr., 17, 125 (1956).

20. L. Gordon, M. L. Salutsky and H. H. Willard, Precipitation From Homogeneous Solution, John Wiley, New York, 1959.

21. M. L. Salutsky and L. L. Qui17, J. Am. Chem. Soc., 72, 3306 (1952).

22. F. H. Verhoek, J. Am. Chem. Soc., 56, 571 (1934).

23. L. L. Quil1 and M. L. Salutsky, Ana1. Chem., 24, 1453 (1952).

24. E. L. Head and C. E. Holley, Jr., "The Precipitation and Thermal Decomposition of Some Rare Earth Carbonates", in Rare Earth Research II, K. S. Vorres, Ed., Gordon and Breach, New York, 1964; see also U.S. Atomic Energy Comm. Rept. LADC-5579 (1962).

25. R. G. Charles, J. Inorg. Nucl. Chem., 27, 1489 (1965).

26. W. W. Wendlandt and T. D. George, Texas J. Sci., 13, 316 (1961).

27. A. A. Trofimovich and G. A. Sedel'nikov, Russ. J. Inorg. Chem., 8, 652 (1963).

28. F. Trombe, M. Blaise and P. Caro, C. R. Acad. Sci. Paris, 263, 521 (1966).

29. D. E. Ryabchikov and E. A. Terentyeva, "Recent Soviet Research on the Chemistry of Rare Earth Complexes" in Progress In The Science and Technology of the Rare Earths, L. Eyring, Ed., Macmi1lan, New York, 1964, Vol. 1, p. 139.

30. J. Griffith, Columbia University, private communication.

31. C. K. Chiang, J. R. Bethin, A. L. Dragoo, A. D. Franklin and K. F. Young, "Electrical Conductivity of $Y$-doped $\mathrm{CeO}_{2}$ Ceramics: Comparison of ac and dc Measurements", to be published. 
32. Electron microprobe analys is was performed by D. E. Newbury, Gas and Particulate Science Division, NBS.

33. STEM analysis was performed by J. Drennan, Imperial College, London.

34. X-ray fluorescence analysis was performed with the assistance of June M. Epp and in collaboration with P. A. Pella, Gas and Particulate Science Division, NBS.

35. The lattice constant was determined in collaboration with C. R. Hubbard, Ceramics, Glass and Solid State Division, NBS.

36. M. C. Morris, H. F. McMudie, E. J. Evans, B. Paretzkin, J. H. deGroot, D. R. Hubbard and S. J. Carmel, Standard X-Ray Diffraction Powder Patterns, NBS Monograph 25, Section 16, U.S. Dept. of Commerce, October 1979.

37. A. Taylor and H. Sinclair, Proc. Phys. Soc. (London), $\underline{57}, 126$ (1945).

38. J. B. Nelson and D. P. Riley, Proc. Phys. Soc. (London), 57, 160 (1945).

39. A. S. Kirillov, Dok1. Akad. Nauk SSSR, 159, 1048 (1964); ASTM Powder Diffraction Card No. 17-503.

40. H. P. Klug and L. E. Alexander, X-Ray Diffraction Procedures, 2nd edition, John Wiley, New York, 1974, p. 297, 634-42, $687-700$.

41. F. Scherrer, Nachr. Ges. Wiss. Goettingen, 1918, 96.

42. A. R. Stokes and A. J. C. Wilson, Proc. Camb. Phil. Soc., 38, 313 (1942).

43. J. Drennan, "A Preliminary Study of $\mathrm{Y}$-Doped $\mathrm{CeO}_{2}$ by Means of the JEOL-100CX Transmission/Scanning/Analytical Microscope", Internal Recort, Imperial College, London, August 1979. 
44. J. D. McCullough and J. D. Britton, J. Am. Chem. Soc., 74, 5225 (1952).

45. J. D. McCullough, J. Am. Chem. Soc., 72, 1386 (1950).

46. G. Brauer and H. Gradinger, Z. Anorg. Allg. Chem., 276, 209 (1954).

47. D. J. M. Bevan, W. W. Barker and R. L. Martin, "Mixed Oxides of the Type $\mathrm{MO}_{2}$ (Fluorite) $-\mathrm{M}_{2} \mathrm{O}_{3}$. Part 2, Non-Stoichiometry in Ternary Rare-Earth 0xide Systems. Part A. The System $\mathrm{CeO}_{2}-\mathrm{Y}_{2} \mathrm{O}_{3}$ ", Rare Earth Research, L. Eyring, Ed., Gordon and Breach, New York, 1965, Vol. 3, p. 441.

48. H. T. Anderson and B. J. Wuensch, J. Am. Ceram. Soc., 56, 285 (1973).

49. K. E. Adham, "Study of the Electrical Properties of ElectroChemical Cells of the Type $\mathrm{O}_{2}, \mathrm{Ag} / \mathrm{CeO}_{2}$-Based Solid Electrolyte/ $\mathrm{Ag}, \mathrm{O}_{2}$ ", D. Engr. Thesis, Universite de Grenoble, 1978.

50. P. H. Bottelberghs, Solid Electrolytes, P. Hagenmuller and W. van Gool, Eds., Academic Press, New York, 1978.

51. J. E. Bauerle, J. Phys. Chem. Sol., 302657 (1969).

52. E. Schouler, M. Kleitz and C. Desportes, J. Chim. Phys., 70, 923 (1973).

53. K. S. Cole and R. H. Cole, J. Chem. Phys., 9, 341 (1941).

54. R. W. Powers and S. P. Mitoff, J. Electrochem. Soc., 122, 226 (1975).

55. A. Hooper, J. Phys. D: App1. Phys., 10, 1487 (1977).

56. I. D. Raistrick, Chun Ho and R. A. Huggins, J. Electrochem. Soc., $\underline{123}, 1469$ (1976).

57. A. D. Frankl in and K. F. Young, J. Electrochem. Soc., 124, 871 (1977). 
58. R. D. Armstrong, T. Dickinson and P. M. Willis, J. Electroanal. Chem., 53, 389 (1974).

59. V. Levitskif, A. Hammou, M. Duclot and C. Desportes, J. Chim. Phys., $\underline{73}, 305$ (1976).

60. V. Levitskii, A. Hammou and M. Duclot, J. Sol. State Chem., 21, $13(1977)$.

61. A. D. Franklin, S. Marzullo and J. B. Wachtman, Jr., J. Rsch. Nat. Bur. Stand., Sect. A., 1ㅡ, 355 (1967).

62. H. B. Johnson, G. R. Miller and I. B. Cutler, J. Am. Ceram. Soc., 50, 526 (1967).

63. K. E. D. Wapenaar and J. Schoonman, J. Sol. State Chem., 25, 31 (1978).

64. U. V. Alpen and M. F. Bell, J. Electroanal. Chem., 99, 85 (1979).

65. N. M. Beekmans and L. Heyne, Electrochimica Acta, 21, 303 (1976).

66. S. H. Chu and M. A. Seitz, J. Sol. State Chem., 23, 297 (1978).

67. L. C. De Jonghe, J. Mat1. Sci., 14, 33 (1979).

68. L. K. H. van Beek, Progress in Dielectrics, $\underline{7}, 67$ (1967).

69. A. L. Dragoo and L. P. Domingues, J. Am. Ceram. Soc., to be submitted.

70. R. T. Dirstine, R. N. Blumenthal and T. K. Kuech, J. Electrochem. Soc., 126, 264 (1979).

71. A. S. Nowick, Da. Yu. Wang, D. S. Park and J. Griffith, Fast Ion Transport in Solids, P. Vashishta, J. N. Mundy and G. K. Shenoy, Eds., Elsevier North-Holland, New York, 1979, ว. 673 .

72. L. H. Bennett, C. K. Chiang, M. I. Cohe, A. L. Dragoo, A. D. Franklin and A. J. McAlister, Annual Report on Materials for Fuel Cells, NBSIR 80-1991, January to December 1978. 
73. C. K. Chiang, A. D. Oragoo and A. D. Franklin, "Slow Transient Phenomenon in $\mathrm{Y}$-Doped $\mathrm{CeO}_{2} "$, in Fast Ion Transport in Solids, P. Vashishta, J. Mundy and G. Shenoy, Eds., Elsevier NorthHolland, New York, 1979.

74. A. H. Heuer, J. Am. Ceram. Soc., 62, 226 (1979).

75. We are indebted to Prof. A. H. Heuer of Case Western Reserve University for providing these specimens in their heat-treated and quenched condition.

76. C. F. Grain, J. Am. Ceram. Soc., 50, 288 (1967).

77. W. Feduska, A. O. Isenberg, J. E. Bauerle, Y. Ishikawa, R. J. Ruka,

S. A. Zeitman and G. E. Zymbaly, Annual Report on Thin Film Fuel Cel1/Battery Power Generating System, C-1197-13, Westing house Corp. April 1978 to March 1979.

78. E. H. Rhoderick, Metal-Semiconductor Contacts, Clarendon Press, Oxford, 1979.

79. D. P. Karim and A. T. Aldred, Phys. Rev. B., 202255 (1979).

80. L. H. Bennett, M. I. Cohen, A. L. Dragoo, A. D. Franki in, A. J. McAlister and K. F. Young, Annual Report on Materials for Fuel Cel1s, NBSIR 78-1472, January to December 1977. 
U.5. OEPT, OF COMM.

BIBLIOGRAPHIC DATA

SHEET (See in structions)

4. TITLE AND SUBTITLE

Materials for Fuel Cells

Annual Report--January 1979 to December 1979

5. AUTHOR(S)

C. K. Chiang, M. I. Cohen, A. L. Dragoo, and A. D. Frankl in

6. PERFORMING ORGANIZATION (If joint or other than NBS, see instructions)

NATIONAL BUREAU OF STANDARDS

DEPARTMENT OF COMMERCE

WASHINGTON, D.C. 20234

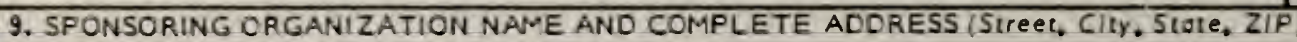

7. ContracU Grant No.

8. Type of Report \& Period Covered

10. SUPPLEMENTARY NOTES

Document describes a computer program; SF-185, FIPS Software Summary, is attached.

11. ABSTRACT (A 200-word or less factual summary of most significant information. If document includes a significant bibliography or literature survey. mention it here)

This report covers work on the preparation of yery dense $\mathrm{Y}$-doped $\mathrm{CeO}_{2}$ (YDC) ceramics; ac impedance studies of YDC, partially stabilized zirconia (Mg-doped) and $\mathrm{Sr}$-doped $\mathrm{LaCrO}_{3}$; a theoretical analysis of current-initiation induced voltage transients in YDC four-probe specimens; and the adaptation of a microprocessor-controlled potentiostat to low-frequency solid electrolyte measurements.

12. KEY WORDS (Six to twelve entries; alphabetical arder: capitalize only proper names; and seporate key words by semicolons) Solid electrolytes; Yttrium-doped ceria; Magnesium-doped zirconia; Strontiumdoped lanthanum chromite; ac impedance spectroscopy; Microprocessor-controlled potentiostat: Interconnector materials.

13. AVAILABILITY

Unlimited

X For Official Distribution. Do Not Release to NTIS

$\square$ Order From Superintendent of Documents, U.S. Government Printing Office, Washington, D.C. 20402.

Z Order From National Technical Information Service (NTIS). Springfisld, VA. 22161

14. NO. OF PRINTED PAGES

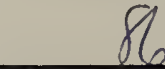

15. Price 

